\title{
Yolk-Shell Nanostructures: Syntheses and Applications for Lithium-Ion Battery Anodes
}

\author{
Geon Dae Moon \\ Dongnam Regional Division, Korea Institute of Industrial Technology, Busan 46938, Korea; gmoon@kitech.re.kr; \\ Tel.: +82-55-912-0333
}

Received: 6 March 2020; Accepted: 2 April 2020; Published: 3 April 2020

\begin{abstract}
Yolk-shell nanostructures have attracted tremendous research interest due to their physicochemical properties and unique morphological features stemming from a movable core within a hollow shell. The structural potential for tuning inner space is the focal point of the yolk-shell nanostructures in a way that they can solve the long-lasted problem such as volume expansion and deterioration of lithium-ion battery electrodes. This review gives a comprehensive overview of the design, synthesis, and battery anode applications of yolk-shell nanostructures. The synthetic strategies for yolk-shell nanostructures consist of two categories: templating and self-templating methods. While the templating approach is straightforward in a way that the inner void is formed by removing the sacrificial layer, the self-templating methods cover various different strategies including galvanic replacement, Kirkendall effect, Ostwald ripening, partial removal of core, core injection, core contraction, and surface-protected etching. The battery anode applications of yolk-shell nanostructures are discussed by dividing into alloying and conversion types with details on the synthetic strategies. A successful design of yolk-shell nanostructures battery anodes achieved the improved reversible capacity compared to their bare morphologies (e.g., no capacity retention in 300 cycles for Si@C yolk-shell vs. capacity fading in 10 cycles for Si@C core-shell). This review ends with a summary and concluding remark yolk-shell nanostructures.
\end{abstract}

Keywords: yolk-shell; templating; self-templating; battery anode; nanomaterial

\section{Introduction}

Energy storage from renewable energy production to electrical energy upgrades the status of lithium-ion batteries to a more significant position due to its large capacity, long lifespan, and high energy density [1]. Among the configuration of rechargeable batteries, the anode is an important part in lithium/sodium-ion batteries in terms of the following requirements: 1) high specific surface area for higher lithium/sodium ion insertion channels, 2) low volume change during charge/discharge for good cycling stability and safety, 3) large pore size and short path for high rate capability, 4) low internal resistance for fast charging, 5) low intercalation potential for $\mathrm{Li}$ or $\mathrm{Na}, 6$ ) price competitiveness, and 7) environmentally-friendliness [2-4]. Since the commercial use of graphite as anode material in LIB, its low gravimetric capacity (graphite, $372 \mathrm{mAh} / \mathrm{g}$ ) provoked the exponentially-increasing R\&D needs for high capacity anode materials to meet the requirement of high energy density lithium-ion batteries for electrical vehicles, smart grid systems, and aerospace applications. An urgency to replace the conventional graphite anodes focused research efforts into lithium metal with higher energy density. Even though lithium metal has one of the highest capacities and the lowest potential, safety issues keep the use of lithium as anode material in LIB due to dendrite formation on lithium metal leading to short-circuit. Thus, alternative candidates have been emerging as new anode materials to tackle the safety problem. Based on the way of Li-ion storage, anode materials are classified into alloying 
anodes $\left(\mathrm{Si}, \mathrm{Sn}, \mathrm{Ge}, \mathrm{Al}, \mathrm{SnO}_{2}\right.$ ), intercalating anodes (carbon, $\left.\mathrm{TiO}_{2}, \mathrm{LTO}\right)$, and conversion reaction anodes (transition metal oxides, chalcogenides, phosphides, nitrides).

Compared to bulk silicon anode, nanoscale silicon materials have been demonstrated as an effective strategy since nanostructured $\mathrm{Si}$ can accommodate elevated mechanical stress leading to prolonged cycling stability. Nevertheless, such nanostructured Si anodes still suffer from short cycle life due to the loss of active material and increased cell impedance at high mass loading $[5,6]$. Other alloy-based anode materials, such as $\mathrm{Sn}$ and Ge, have long been considered as alternatives due to their high specific capacities and lower operating potentials than graphite. In addition, tin has low electrical resistivity $\left(1.1 \times 10^{-7} \Omega \cdot \mathrm{m}\right)$. Tin and germanium are also prone to severe capacity degradation and short cycle life, caused by their large volume changes during lithiation/delithiation, subsequent pulverization, the formation of SEI, inhibition of $\mathrm{Li}^{+} /$electron transport, and delamination from current collector $[7,8]$. Metal oxides are also a promising family of anode materials since they have a safer lithiation potential that eliminates the problematic lithium dendrite formation during charging. However, the low electrical conductivity of metal oxides demands the conductive material in anode structures. Nanostructured metal oxides and their composites with various carbon materials have been used to improve their capacity retention by suppressing phase segregation, volumetric expansion, and ionic/electronic transport [9]. There have been recent research efforts to develop other anode materials including metal chalcogenides, phosphides, and nitrides. Like other transitional metal oxides, these metal compound anodes are based on the conversion reaction. Although these metal compounds have higher operating potential than graphite, they are still attractive candidates due to higher theoretical capacities [2,10-14].

Unlike the intercalating-type anodes with ignorable volume expansion, the chemical reaction between the anode with lithium ions accompanies serious volume change leading to an increase of internal resistance and rapid capacity decay. Due to the large volume change during charging/discharging in the anode, there needs to protect active material from fracture or dendrite formation. A number of structures have also been investigated in order to boost the capacity of lithium/sodium-ion batteries $[15,16]$. As one of the successful ways, researchers have paid attention on designing yolk-shell nanostructure to place active anode materials in hollow protecting layers [17-20]. Various research has already been done on the yolk-shell nanostructures for applications of drug delivery, sensor, and catalyst [21-24]. Different from core-shell structure in dense contact, yolk-shell nanostructures create movable space inside the protecting shell, which enables anode to expand without fragmentation or dendrite formation during a chemical reaction. Thus, yolk-shell nanostructures are beneficial for improving electrochemical performance owing to various merits including buffering space, large surface area, and short diffusion path.

In this review, we will provide a recent progress of battery anode materials based on yolk-shell nanostructures. For the starter, we give a general explanation on the development of how to build up yolk-shell nanostructures through templating and self-templating approaches. Then, we move on to discuss various yolk-shell nanostructures for application in lithium-ion battery anodes. Lastly, the concluding remark follows in the conclusion and outlook.

\section{Building Yolk-Shell Nanostructure}

Yolk-shell nanostructures indicate a class of hybrid materials consisting of a hollow shell encircling movable cores with the void. The hollow nanostructures containing different nanoparticles inside possess unique morphological features, which bring low density, large surface area, and great loading capacity. In addition, the yolk-shell nanostructures can create hybrid materials with complex functions for specific purposes by integrating various functional components into this system. Thus, a lot of attention has been paid to this promising structure since it has great potential for diverse applications in catalysis, nanoreactors, drug delivery, and energy storage [25-30]. The existence of the void inside allows the exposure of the inner materials with a protective effect of the shell, which is advantageous in the preservation of the core materials. The void space in the yolk-shell nanostructures can serve as 
a storage space for functional cargoes and as a reaction room for chemical reactions. Compared to the conventional core-shell structures, the yolk-shell nanostructures offer additional availability for the tuning of materials. As is depicted in the Scheme 1, the yolk-shell morphologies can be achieved by straightforwardly templating methods as well as self-templating syntheses without additional templates for the formation of the cavity.

\section{Templating}
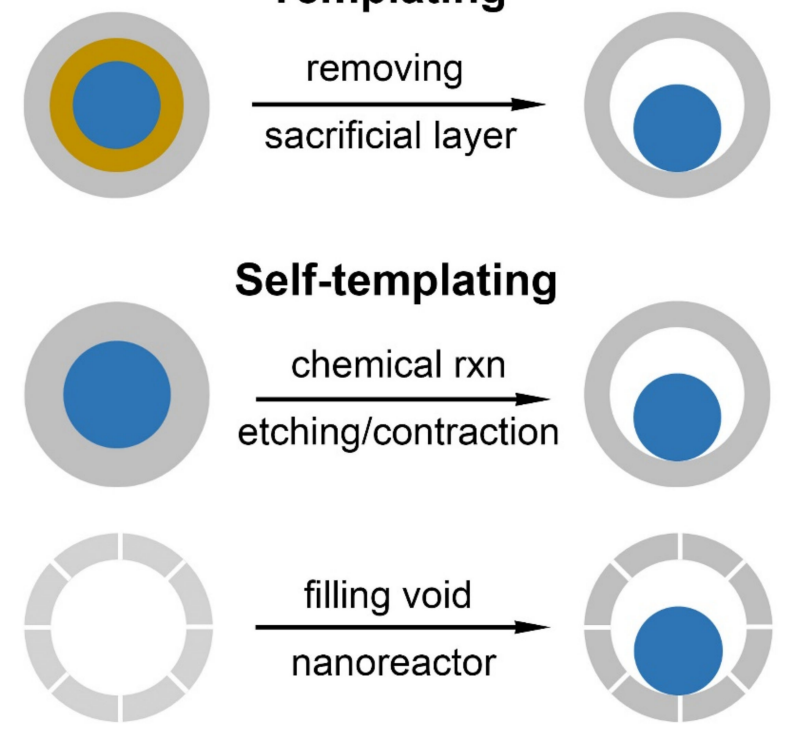

Self-templating

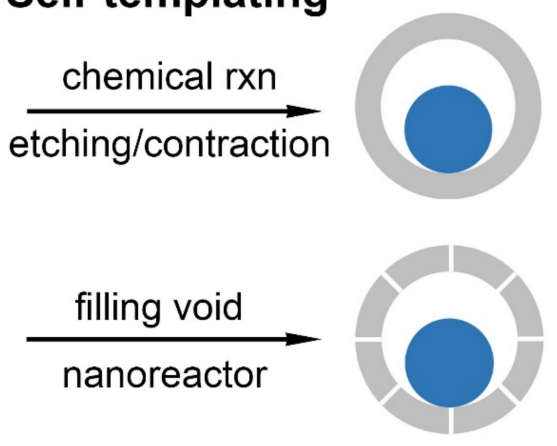

Scheme 1. Synthetic strategies towards yolk-shell nanostructures categorizing into the templating and the self-templating approaches.

\subsection{Templating Methods}

Templating method is the most common approach for building up yolk-shell nanostructures because it is conceptually straightforward in a way that templates can be removed leaving the cavity inside the shell. Templating synthesis is classified into hard-templating and soft-templating based on the kind of template materials, i.e., rigid or soft. Generally, templating approaches follow the steps below: formation of the core, template coating, coating of the outer layer, and removal of the sacrificial template. In some cases, the surface modification is necessary for the coating of the outer layer to confer suitable surface properties. The removal of the template can be done through chemical etching, solvent dissolution, and calcination to obtain the cavity inside the hollow shell. Figure 1A shows the synthetic scheme of yolk-shell nanostructured $\mathrm{Au}_{\mathrm{T}} \mathrm{TiO}_{2}$ morphology for the cryogenic oxidation reaction catalyst of carbon monoxide [31]. Gold nanoparticles acting as the yolk were first coated with silica to form $\mathrm{Au} @ \mathrm{SiO}_{2}$ core-shell nanostructure through a sol-gel process. Then, an outer titania shell was deposited on the surface of silica using tetrabutyl titanate (TBOT) to generate $\mathrm{Au} @ \mathrm{SiO}_{2} @ \mathrm{TiO}_{2}$ double-shell nanostructure. Finally, the silica was etched away by using an alkaline solution to create the void with the $\mathrm{Au} @ \mathrm{TiO}_{2}$ yolk-shell nanostructure. The resultant image of $\mathrm{Au} @ \mathrm{TiO}_{2}$ yolk-shell nanostructures is displayed in the TEM images of Figure 1B,C. The use of Au nanoparticles in catalyst has one limitation, which they are easy to sinter due to the size effect. This leads to the severe degradation of catalytic activity. Thus, the authors adopted the yolk-shell architecture as an appropriate nanoreactor for the catalytic reaction since the titania shell can isolate the gold nanoparticles from clustering and guarantee the transfer of gases in and out of the inner space for sufficient access to gold surfaces. Typical materials for templating are silica, carbon, metal, metal oxides, and oligomers [32,33]. Silica is one of the most frequently used hard templates for the fabrication of yolk-shell nanostructures due to its easy removal with alkali or hydrogen fluoride treatment. For example, Shi and co-workers reported that $\mathrm{Au} @ \mathrm{mSiO}_{2}$ and ellipsoidal $\mathrm{Fe}_{2} \mathrm{O}_{3} @ \mathrm{mSiO}_{2}$ yolk-shell nanostructures by using sodium carbonate and ammonia solution as the etching agent [34]. 
Carbon has also been used as a hard template due to its easy removal through calcination. Spindle $\mathrm{Fe}_{2} \mathrm{O}_{3} @ \mathrm{mSiO}_{2}$ yolk-shell nanostructures were reported by using carbon as the sacrificial template [23]. In general, the firstly-coated shell act as a sacrificial template to generate voids inside the hollow shells after the removal process. However, the innermost core material can also behave as the removal template for the formation of desired materials inside hollow shells. Figure 1D exhibits the schematic procedure of fabricating platinum nanoparticle-decorated hollow silica shell [35]. The platinum layer was coated on the surface of amorphous selenium colloids through chemical reduction in alcohol. Then, the Stöber process produces the silica coating on the surface of Pt shell to finally form Se@Pt@SiO double-shelled structures. The innermost core was removed by dissolving in appropriate solvent like alcohol and hydrazine. During the removal process, the Pt layer go through transformation into $\mathrm{Pt}$ nanoparticles depending on the material flux. While the slow dissolution of Se core tends to preserve the thin Pt layer, the high flux of the core induces the rearrangement of the Pt clusters into nanoparticles ranging from a few to tens of nanometers by adjusting the temperature and the solubility of the Se core in solvents.

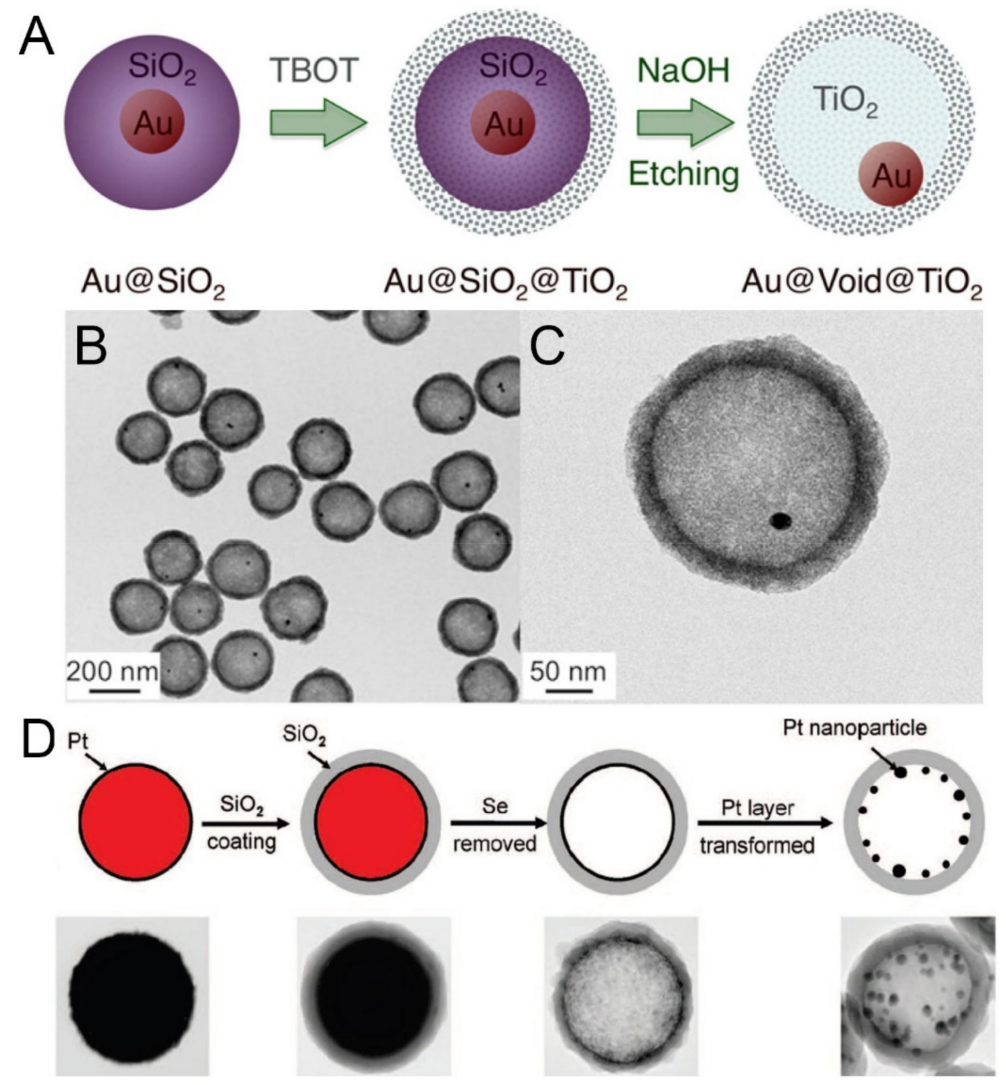

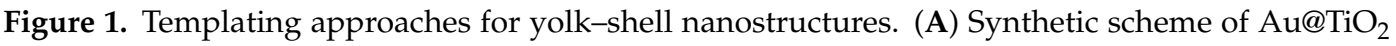

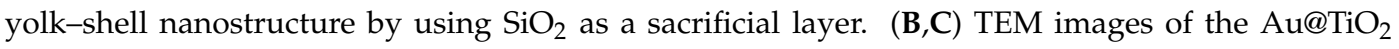
yolk-shell after etching the $\mathrm{SiO}_{2}$ layer. Reproduced with permission from [31]. Copyright Elsevier Ltd, 2016. (D) Decoration of interior surfaces in the $\mathrm{SiO}_{2}$ hollow shell by exploiting amorphous Se colloids as a template. Reproduced with permission from [35]. Copyright American Chemical Society, 2008.

\subsection{Self-Templating Methods}

Unlike the conventional templating methods, direct syntheses of yolk-shell nanostructures have also been developed by self-templating approaches. The self-templating methods can contain the following categories: galvanic replacement, Kirkendall effect, Ostwald ripening, partial removal of the core, core injection, core contraction, and surface-protected etching. The galvanic replacement reaction happens at the interface of metals with the different electrical potential, in which one metal serves as a reducing agent and the other metal serves as an oxidizing agent, respectively. As a result, 
the metal with low reduction potential tends to oxidize by reducing the other metal ion into a reduced form. Generally, the core metal is coated with other metal which has higher reduction potential. Upon addition of the metal ions, the core metal tends to dissolve in the solution while the metal ions are reduced and plated on the surface of the core metal. Xia and co-workers reported the synthesis of $\mathrm{Au} / \mathrm{Ag} @ \mathrm{Au} / \mathrm{Ag}$ yolk-shell nanostructures based on the reduction potential difference between Au and Ag [36]. Figure 2 shows the illustration of the process for fabricating Au@Au/Ag yolk-shell nanostructure starting from Au@Ag core-shell through the galvanic replacement reaction [37]. During the reaction, the $\mathrm{Ag}$ shell is transformed into $\mathrm{Au} / \mathrm{Ag}$ alloy by creating the hollow void between the core and the shell. The Kirkendall effect is also an efficient way to prepare yolk-shell nanostructures since the motion of the interface between two materials occurs due to different diffusion rates of atoms or ions. Alivisatos and co-workers reported that Au@iron oxide yolk-shell nanoparticles can be synthesized through the Kirkendall effect [38]. This process starts with the deposition of an iron shell on an Au core, followed by the oxidation of the iron shell into a hollow iron oxide shell as well as void formation inside. Ostwald ripening is also a well-known reaction that involves the dissolution of small crystals and the redeposition of the dissolved species on the surfaces of larger crystals. Recently, Caruso and co-workers demonstrated that titania@ammonium titanate yolk-shell nanostructures can be synthesized by the self-templating approach based on the Ostwald ripening mechanism [39]. A little more straightforward self-templating method is the partial removal of the core from core-shell structures. Core-shell structures with a core material being able to etched or dissolved can create void space inside the shell of the core-shell morphology. For example, Paik and co-workers reported the synthesis of $\mathrm{Fe}_{3} \mathrm{O}_{4} @ \mathrm{C}$ yolk-shell nanocubes through the partial removal approach [40]. $\mathrm{Fe}_{2} \mathrm{O}_{3}$ nanocubes were coated with a PDA layer to form $\mathrm{Fe}_{2} \mathrm{O}_{3} @ P D A$ core-shell nanocubes, followed by annealing at $500{ }^{\circ} \mathrm{C}$ to transform into $\mathrm{Fe}_{2} \mathrm{O}_{3} @ \mathrm{C}$ core-shell structures. Then, the $\mathrm{Fe}_{2} \mathrm{O}_{3}$ core was partially etched to create a cavity inside by using hydrochloric acid. Yi Cui and co-workers have demonstrated the synthesis of sulphur@ $\mathrm{TiO}_{2}$ yolk-shell nanostructures through a partial dissolution of sulfur core in toluene [41]. The sulphur particles were coated with $\mathrm{TiO}_{2}$ through hydrolysis of titanium diisopropoxide bis(acetylacetonate) in solution to form sulphur@ $\mathrm{TiO}_{2}$ core-shell structures. The following partial dissolution of sulfur in toluene creates an empty space between the sulfur core and the $\mathrm{TiO}_{2}$ shell, resulting in the yolk-shell shape. The internal void space can accommodate the volume expansion of sulphur by preserving the sulfur core from cracking and fracture inside the shell.

Yolk-shell morphology can also be synthesized through injecting the core material in a hollow shell from outside of the shell via transport along the pores. In this approach, the hollow shell act as the nanoreactors to confine and control the synthesis of the core, leading to the core-shell morphology with cavity [42]. Chen and co-workers have demonstrated the upconverting luminescent yolk-shell nanostructures by incorporating lanthanide-doped upconversion nanoparticles into hollow mesoporous silica [43]. Firstly, hollow mesoporous silica shell was prepared by a selective etching approach with an aid of a cationic surfactant. Then, the lanthanide-doped upconversion nanoparticles were synthesized within the hollow silica by loading precursor and calcination process to generate the core material inside. Lianjun Wang and co-workers have also demonstrated the yolk-shell nanostructure through an impregnation into a pre-formed hollow mesoporous silica nanosphere (Figure 3A,B) [44]. Fe@SiO 2 yolk-shell nanospheres were synthesized by a sequential two-solvents impregnation-reduction method. Figure 3C shows the TEM image of the $\mathrm{Fe}_{\mathrm{SiO}}$ yolk-shell nanosphere after the impregnation-reduction reaction. Lipid vesicles are also great nanoreactors for the synthesis of yolk-shell nanostructures through loading the core precursor in a hollow shell. Pinkhassik and co-workers reported the yolk-shell nanostructured Ag@polymer by using liposomes as the nanoreactors (Figure 3D,E) [45]. Liposomes with monomers and a photoinitiator in the bilayer and silver ions in the aqueous core were prepared by hydrating a mixture of lipids and monomers with a silver nitrate solution. The polymerization begins at the application of UV light and Ag nanoparticles starts to form with the aid of a photoinitiator. Finally, Ag@polymer yolk-shell nanostructure can be obtained. Likewise, Au@polymer yolk-shell nanostructures were also reported by loading reductant in 
a hollow nanocapsules [46]. Core contraction has also been studied as another promising strategy for synthesizing yolk-shell nanostructures. For example, the $\mathrm{SnO}_{2}$ yolk-shell particles were synthesized by spray pyrolysis at high temperature. The carbonization of sucrose within the precursor droplets changed into $\mathrm{C}-\mathrm{SnO}_{2}$, followed by coating of $\mathrm{SnO}_{2}$ layer to form $\mathrm{C}-\mathrm{SnO}_{2} @ \mathrm{SnO}_{2}$ core-shell structures. Then, the combustion process induced the contraction of the $\mathrm{C}-\mathrm{SnO}_{2}$ core to create void in the $\mathrm{SnO}_{2}$ shell. Other than the above methods, there have been other approaches to synthesize yolk-shell nanostructures such as surface-protected etching, fluid leakage, and hot-water-induced dissolution and reassembly [47-49].

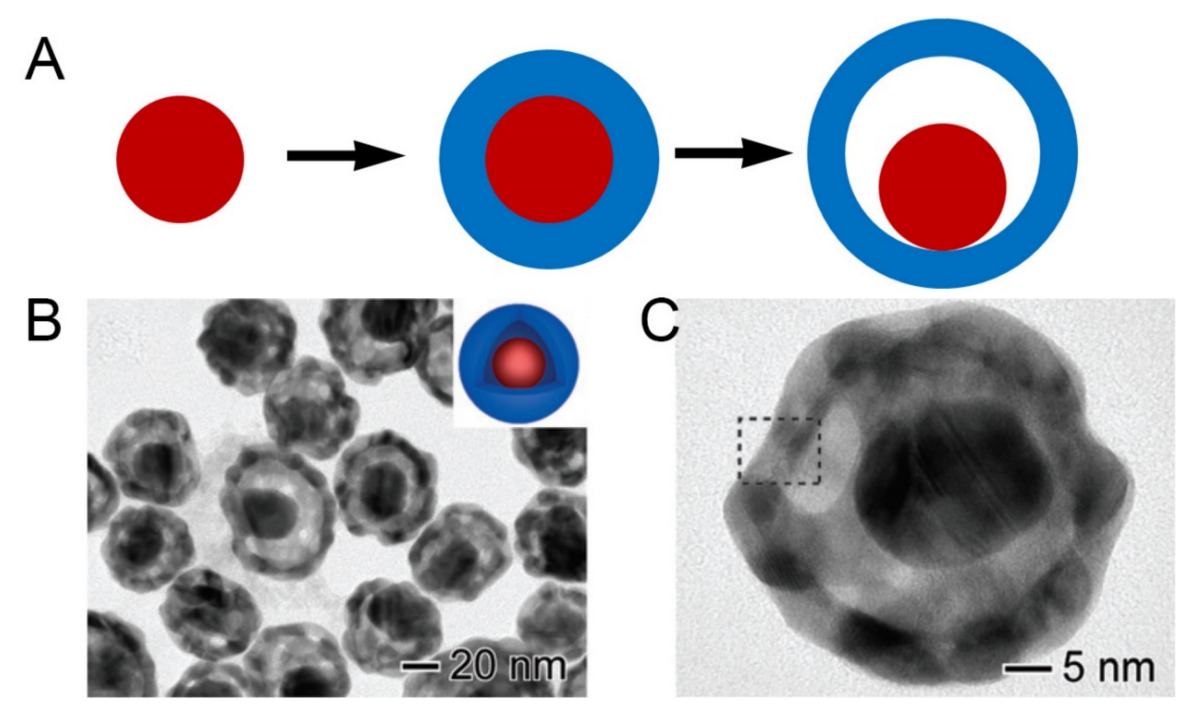

Figure 2. Self-templating syntheses for yolk-shell nanostructures. (A) Scheme illustrating the procedure for the Au core and $\mathrm{Au} / \mathrm{Ag}$ alloy shell through the galvanic replacement reaction. (B,C) TEM images of Au@Au/Ag yolk-shell nanostructure. Reproduced with permission from [37]. Copyright Wiley-VCH, 2016.
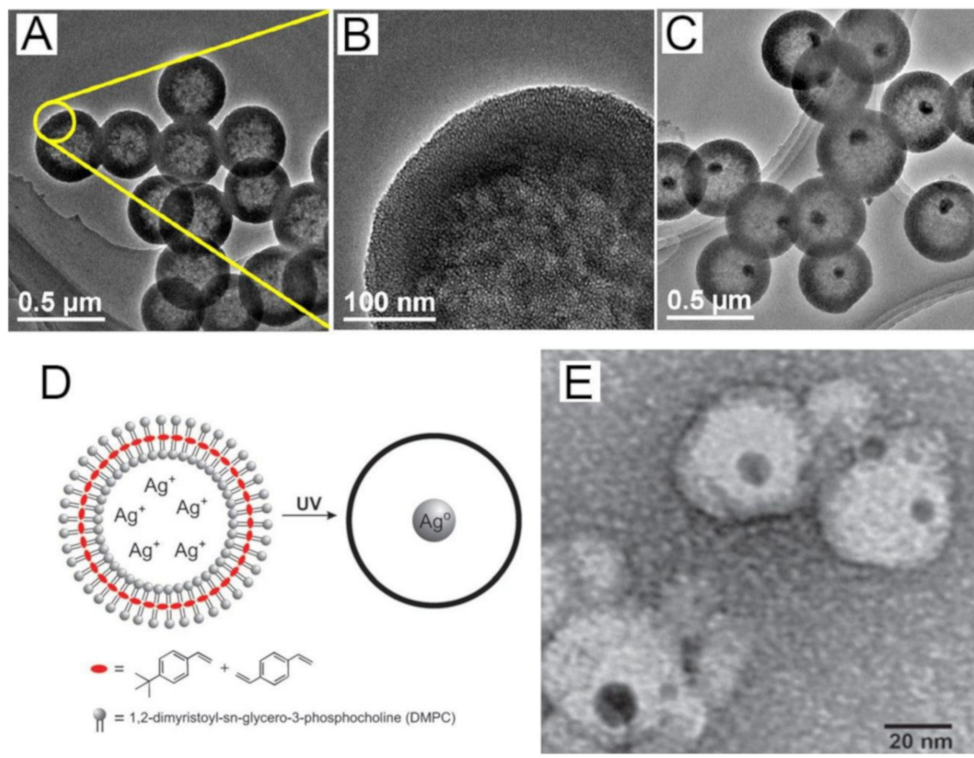

Figure 3. Self-templating syntheses for yolk-shell nanostructures. (A-C) TEM images of the hollow mesoporous silica (HMS) containing Fe nanoparticle prepared by a sequential two solvents impregnation-reduction reaction. Reproduced with permission from [44]. Copyright American Chemical Society, 2014. (D) Preparation of polymer nanocapsules loaded with Ag nanoparticles through a free-radical photoinitiator. (E) TEM image of nanocapsules containing the Ag yolk particles. Reproduced with permission from [45]. Copyright The Royal Society of Chemistry, 2010. 


\section{Yolk-Shell Nanostructured Anodes}

For the next-generation Li rechargeable batteries, the most ideal anode material for lithium rechargeable batteries is lithium meal in terms of the lowest anode potential ( $-3.04 \mathrm{~V}$ vs. SHE), high specific capacity $(3860 \mathrm{mAh} / \mathrm{g})$, lightweight $\left(0.53 \mathrm{~g} / \mathrm{cm}^{3}\right)$, and no demand for Cu current collector [50]. The uncontrolled dendrite formation in Li metal anodes has become a hurdle against the practical employment [51]. The sharp Li dendrite can grow through the separator during the cycle, thus leading to an internal short circuit. Recent research to tackle this problem relies on solid electrolyte interphase stabilization/modification by adding additives or conducting scaffold to form stable SEI [52,53]. The safety issue is still not fully resolved for mass production in industries. As an alternative, lithium alloy-based materials have been investigated due to their higher theoretical capacities $(4200 \mathrm{mAh} / \mathrm{g}$ for $\mathrm{Si}, 1,623 \mathrm{mAh} / \mathrm{g}$ for $\mathrm{Ge}, 994 \mathrm{mAh} / \mathrm{g}$ for $\mathrm{Sn}$, and 2,235 mAh/g for Al) and low operating potentials $\left(\sim 0.5 \mathrm{~V}\right.$ vs. $\mathrm{Li} / \mathrm{Li}^{+}$for $\left.\mathrm{Si}\right)$ than graphite leading to greater energy and power densities [54]. However, alloy-based anodes experience catastrophic capacity fading because of the large volume change upon electrochemical cycling (e.g., $\Delta V_{\mathrm{Si}}=\sim 400 \%$ for full lithiation), which, in turn, may cause electrode pulverization and loss of contact with the current collector.

Despite the second highest abundance of silicon in nature and, thus, viable mass production, graphite anodes still dominate the marketplace due to major challenges preventing its widespread use. First of all, alloy anodes, including $\mathrm{Si}$, undergo significant volume change, which leads to pulverization of the initial particle morphology and loss of electrical contact. Secondly, the low electrochemical potential of alloy-type anodes provokes thick SEI film due to the reductive decomposition of the organic electrolyte [55]. In addition, the SEI rupture from volume change and particle fracture during cycling and an electrolyte is continually consumed by exposing the electrode surface to the electrolyte. This excessive growth of SEI lows Coulombic efficiency by enhancing resistance to ionic and electronic transport. The stabilization of the SEI layer was obtained by surface coating with metal oxide and carbon [56-58]. However, those surface coatings cannot withstand the large volume changes of Si during discharge/charge cycles. Keeping the advantage of the surface coating, a new approach has recently been tried to give spatial room for active material to maintain its initial morphology despite the volume change by creating yolk-shell nanostructures [17-19]. Conversion-based anode materials also experience the large volume change during $\mathrm{Li}$ or $\mathrm{Na}$ insertion/extraction process leading to fast capacity fading. Transition metal oxides and sulfides have been prepared as yolk-shell nanostructures to provide stable SEI formation and increased electronic conductivity, especially when they are covered with carbonaceous materials. In this section, we will discuss the recent development of metals, metal oxides, and metal sulfides based on yolk-shell nanostructures for Li or Na rechargeable batteries. Table 1 shows various lithium/sodium rechargeable anode materials based on yolk-shell nanostructures.

Table 1. Summary of various $\mathrm{Li} / \mathrm{Na}$ rechargeable anode materials constructed as yolk-shell nanostructures. (Pyrolysis: spray pyrolysis, Thermal: thermal treatment, Ripening: Ostwald ripening, LTO: $\left.\mathrm{Li}_{4} \mathrm{Ti}_{5} \mathrm{O}_{12}\right)$.

\begin{tabular}{|c|c|c|c|}
\hline Yolk & Shell & Fabrication & Pros/Cons \\
\hline \multicolumn{4}{|c|}{ Alloy/de-alloy materials } \\
\hline $\mathrm{Si}$ & $\begin{array}{c}\mathrm{C}[17-19,59-63], \\
\mathrm{NiO}[64], \mathrm{SiO}_{2} @ \mathrm{C}[65]\end{array}$ & $\begin{array}{c}\text { Etching [17-19,60-63,65], } \\
\text { Pyrolysis }[59,64]\end{array}$ & \multirow{4}{*}{$\begin{array}{c}\text { high capacity and energy } \\
\text { density, good safety/poor cycling }\end{array}$} \\
\hline Sn & C [66-71] & $\begin{array}{c}\text { Thermal [67-71], } \\
\text { Pyrolysis [66] }\end{array}$ & \\
\hline $\mathrm{SnO}, \mathrm{SnO}_{2}$ & $\mathrm{C}$ [72-75], $\mathrm{SnO}_{2}$ [76] & $\begin{array}{l}\text { Etching }[72,73] \text {, } \\
\text { Thermal [74-76] }\end{array}$ & \\
\hline $\mathrm{Al}$ & $\mathrm{TiO}_{2}$ [77] & Etching [77] & \\
\hline
\end{tabular}


Table 1. Cont.

\begin{tabular}{|c|c|c|c|}
\hline Yolk & Shell & Fabrication & Pros/Cons \\
\hline \multicolumn{4}{|c|}{ Conversion materials } \\
\hline $\mathrm{Co}_{3} \mathrm{O}_{4}, \mathrm{CoMn}_{2} \mathrm{O}_{4}$ & $\begin{array}{c}\mathrm{Co}_{3} \mathrm{O}_{4}[78] \\
\mathrm{CoMn}_{2} \mathrm{O}_{4}[79]\end{array}$ & Pyrolysis [78,79] & \multirow{12}{*}{$\begin{array}{l}\text { high capacity, high energy, } \\
\text { environmentally- } \\
\text { compatibility/low coulombic } \\
\text { efficiency, poor cycling, unstable } \\
\text { SEI formation, } \\
\text { large potential hysteresis }\end{array}$} \\
\hline $\mathrm{Cr}_{2} \mathrm{O}_{3}$ & $\mathrm{TiO}_{2}[47]$ & Thermal [47] & \\
\hline $\mathrm{Fe}_{2} \mathrm{O}_{3}, \mathrm{Fe}_{3} \mathrm{O}_{4}, \mathrm{FeO}_{x}$ & $\begin{array}{c}\mathrm{C} \text { [47,80-82], grapheme } \\
{[44], \mathrm{Fe}_{2} \mathrm{O}_{3}[83]} \\
\mathrm{TiO}_{2}[84]\end{array}$ & $\begin{array}{c}\text { Etching [80-82], } \\
\text { Pyrolysis [83], } \\
\text { Thermal }[44,47,84]\end{array}$ & \\
\hline $\mathrm{MnO}, \mathrm{MnO}_{2}$ & $C[85,86]$ & $\begin{array}{l}\text { Thermal [85], } \\
\text { Etching [86] }\end{array}$ & \\
\hline $\mathrm{MoO}_{2}$ & $\mathrm{MoO}_{2}[87]$ & Ripening [87] & \\
\hline $\begin{array}{l}\mathrm{Ni}, \mathrm{NiO}, \mathrm{NiMoO}_{4}, \\
\quad \mathrm{NiCO}_{2} \mathrm{O}_{4}\end{array}$ & $\begin{array}{c}\mathrm{C} \text { [88], graphene [89], } \\
\mathrm{NiO}[90,91], \mathrm{NiMoO}^{2} \\
{[92], \mathrm{NiCO}_{2} \mathrm{O}_{4}[93]}\end{array}$ & $\begin{array}{c}\text { Etching [89], } \\
\text { Pyrolysis [91,92], } \\
\text { Thermal [88,90,93] }\end{array}$ & \\
\hline $\mathrm{V}_{2} \mathrm{O}_{3}$ & $\mathrm{~V}_{2} \mathrm{O}_{3} @ \mathrm{C}[94]$ & Ripening [94] & \\
\hline $\begin{array}{c}\mathrm{ZnO}, \mathrm{ZnCo}_{2} \mathrm{O}_{4} \\
\mathrm{ZnFe}_{2} \mathrm{O}_{4}, \mathrm{ZnO}-\mathrm{Mn}_{3} \mathrm{O}_{4}\end{array}$ & $\begin{array}{c}\mathrm{C} \text { [95], } \mathrm{ZnO}-\mathrm{NiO} \text { [96], } \\
\mathrm{ZnCo}_{2} \mathrm{O}_{4}[97], \mathrm{ZnFe}_{2} \mathrm{O}_{4} \\
{[98], \mathrm{ZnO} / \mathrm{Mn}_{3} \mathrm{O}_{4}[99]}\end{array}$ & $\begin{array}{c}\text { Pyrolysis [97-99], } \\
\text { Ripening [95,96] }\end{array}$ & \\
\hline $\mathrm{CoS}_{2}, \mathrm{Co}_{9} \mathrm{~S}_{8}$ & $\mathrm{CoS}_{2}[100], \mathrm{Co}_{9} \mathrm{~S}_{8}[101]$ & $\begin{array}{l}\text { Ripening [100], } \\
\text { Pyrolysis [101] }\end{array}$ & \\
\hline $\mathrm{MoSe}_{2}$ & $\mathrm{MoSe}_{2}[102]$ & Pyrolysis [102] & \\
\hline SnS & SnS [103] & Pyrolysis [103] & \\
\hline $\mathrm{Zn}-\mathrm{Fe}-\mathrm{S}$ & Zn-Fe-S [104] & Pyrolysis [104] & \\
\hline \multicolumn{4}{|c|}{ Insertion/de-insertion materials } \\
\hline $\mathrm{TiO}_{2}, \mathrm{Li}_{4} \mathrm{Ti}_{5} \mathrm{O}_{12}$ & $\begin{array}{c}\mathrm{TiO}_{2}[105-107], \mathrm{TiO}_{2}-\mathrm{C} \\
{[108], \mathrm{Li}_{4} \mathrm{Ti}_{5} \mathrm{O}_{12}[109]}\end{array}$ & $\begin{array}{l}\text { Ripening [105-107], } \\
\text { Pyrolysis [109] }\end{array}$ & extreme safety/low capacity \\
\hline
\end{tabular}

\subsection{Alloy-Type Materials}

Alloying/de-alloying anode materials in LiBs and NIBs are attractive for their very high capacities. However, the large volume change upon electrochemical cycling is detrimental to commercializing them, so that several strategies have been developed: designing nanostructures and fabrication of composites with lithium material [110]. To alleviate the fast capacity fading due to electrode pulverization, capping materials, such as conductive carbon or porous metal oxides, can be exploited as a buffer layer to endure the large volume exchange during cycling. Core-shell and yolk-shell nanostructures are the examples in a way to provide the robust wall and surround the active electrode part. In terms of guaranteeing spacious room for nanostructured anode materials to keep their morphologies, yolk-shell nanostructures are advantageous compared to core-shell, which is necessary for alloy-type anode materials due to their very large volume change.

\subsubsection{Silicon}

Nanostructured $\mathrm{Si}$ anodes such as nanoparticles, nanowires, and nanotubes can relieve the huge morphological change and shorten the diffusion path of lithium ions. Nevertheless, pure $\mathrm{Si}$ nanomaterials tend to aggregate during lithiation/delithiation, leading to aggravation of electronic transport [111]. Hybridization of the nanostructured Si with electrochemically inactive matrix is an alternative to pure Si nanostructures. The inactive materials can stabilize Si nanomaterials and prevent the aggregation by alleviating the mechanical stress from huge volume change [112]. Unlike core-shell structured anodes, novel yolk-shell nanostructures have, recently, been on the focus of battery anode materials because the active core (yolk) can expand upon lithiation without breaking the shell and stabilize the SEI layer [18]. Especially, encapsulating Si nanoparticles with carbon 
has been the main idea of fabricating yolk-shell nanostructured Si anode due to its elastic nature and electronic conductivity. Many preparation methods include chemical etching (acid or base) the unnecessary silica or calcium carbonate layer after carbonization to create a void in the yolk-shell nanostructure [17-19,60-63,65].

Cui and co-workers have, successfully, designed a Si@C yolk-shell nanostructure and demonstrated prolonged cycle life by characterizing the in-situ Si nanoparticle expansion during electrochemical lithiation [18]. A successful design for Si anode requires the following prerequisite: nanostructuring of silicon, stable SEI, well-controlled pore, and up-scaled fabrication. Figure 4A shows a comparative scheme between a conventional slurry Si nanoparticle electrode and Si@C yolk-shell electrode. The expansion of Si nanoparticles disrupts the microstructure of the electrode during lithiation in the case of the conventional slurry electrode. The void in the yolk-shell nanostructure allows Si to expand without rupturing the carbon coating layer, which enables a stable and thin SEI layer formation on the outer surface of the carbon. Furthermore, the volume change of the Si does not break the outer shell. The Si@C yolk-shell nanostructure was fabricated by coating, conformally, $\mathrm{Si}$ with $\mathrm{SiO}_{2}$ sacrificial layer and then polydopamine, followed by carbonization with nitrogen doping and selective removal of $\mathrm{SiO}_{2}$ layer in acidic solution (Figure 4B). This completely sealed structure was monitored with in-situ TEM to demonstrate that the Si@C yolk-shell provides excellent electrochemical cycling performance to alleviate the severe volume change of Si during lithiation/delithiation (Figure 4C). Pristine Si nanoparticles (0 s) are visible within the outer C shell. The volume expansion of Si nanoparticles is seen in $105 \mathrm{~s}$ to produce the partially lithiated $\mathrm{Li}_{\mathrm{x}} \mathrm{Si}$ shell/crystalline Si core in the carbon shell. Full lithiation increases the size of Si particles up to 300 nm. Furthermore, the thickness of carbon shell increases from 5 to $\sim 20 \mathrm{~nm}$ after lithiation implying that the carbon coating is also lithiated and creates a thin layer of ionic liquid electrolyte at the surface. Figure 4D shows the reversible capacity of Si@C yolk-shell electrode reached $2833 \mathrm{mAh} / \mathrm{g}$ for the initial cycle at C/10 and stabilized at $\sim 1500 \mathrm{mAh} / \mathrm{g}$ at $1 \mathrm{C}$. No capacity retention was observed in the first 300 cycles and $74 \%$ of the capacity was achieved after 1000 cycles. In contrast, the bare Si nanoparticle and Si@C core-shell electrodes showed very fast capacity fading in the first 10 cycles. The stable SEI formation of the Si@C yolk-shell electrode was evident in the Coulombic efficiency profile.

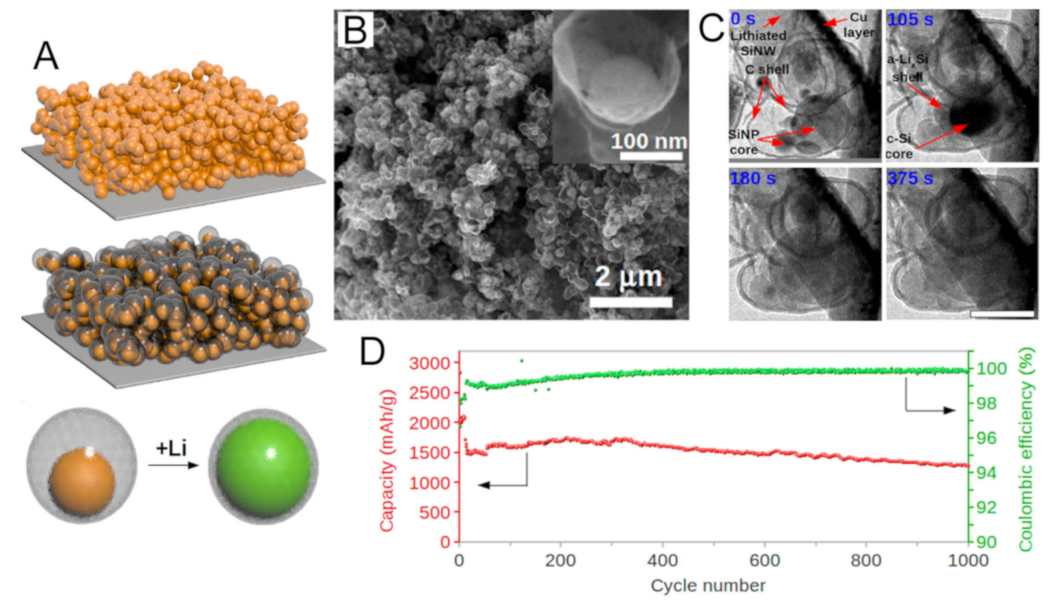

Figure 4. Si@C yolk-shell nanostructure. (A) Comparison of a conventional slurry coated silicon nanoparticle and Si@C yolk-shell electrodes. SEI on the surface of the Si nanoparticles is not stable, leading to failure of the battery in a conventional slurry electrode. The yolk-shell nanostructure creates enough space and allows the Si to expand without rupturing the shell layer. (B) SEM image of Si@C yolk-shell nanostructure. (C) Serial in situ TEM images showing the expansion of the Si yolk part. The scale bar is $200 \mathrm{~nm}$. (D) Delithiation capacity and Coulomb efficiency of the first 1000 galvanostatic cycles between $0.01-1 \mathrm{~V}$ at $1 \mathrm{C}$ rate. Reproduced with permission from [18]. Copyright American Chemical Society, 2012. 
Open-ended mesoporous carbon shell was devised to facilitate the fast diffusion of $\mathrm{Li}^{+}$ions and provide the full immersion of Si core materials in the electrolyte for higher rate capability [63]. Si@mC (mesoporous carbon) yolk-shell nanostructures are developed by Zhang and co-workers by using mesoporous $\mathrm{SiO}_{2}$ as a template, which is etched away later, to form mesoporous carbon shell containing Si nanoparticle in the core (Figure 5). For a comparative study, they prepared two types of $\mathrm{Si} @ \mathrm{mC}$ according to the void space inside the carbon shell (10 and $50 \mathrm{~nm}$ ). The electrochemical cycling properties of Si@mC yolk-shell electrodes outperform the pure Si nanoparticle electrode (Figure 5E). Another notable observation is that enough space inside the carbon shell is important in terms of cycling performance and rate capacity retention. Small void is hard to afford the large volume expansion of Si, which can result in structural collapse of the carbon shell. Thus, the successful design of yolk-shell nanostructure takes into consideration the efficient volume expansion of Si core material. Other than the chemical etching method, spray pyrolysis is another approach to form yolk-shell Si nanostructures, i.e., $\mathrm{Si} @ \mathrm{C}, \mathrm{Si} @ \mathrm{NiO}[59,64]$.
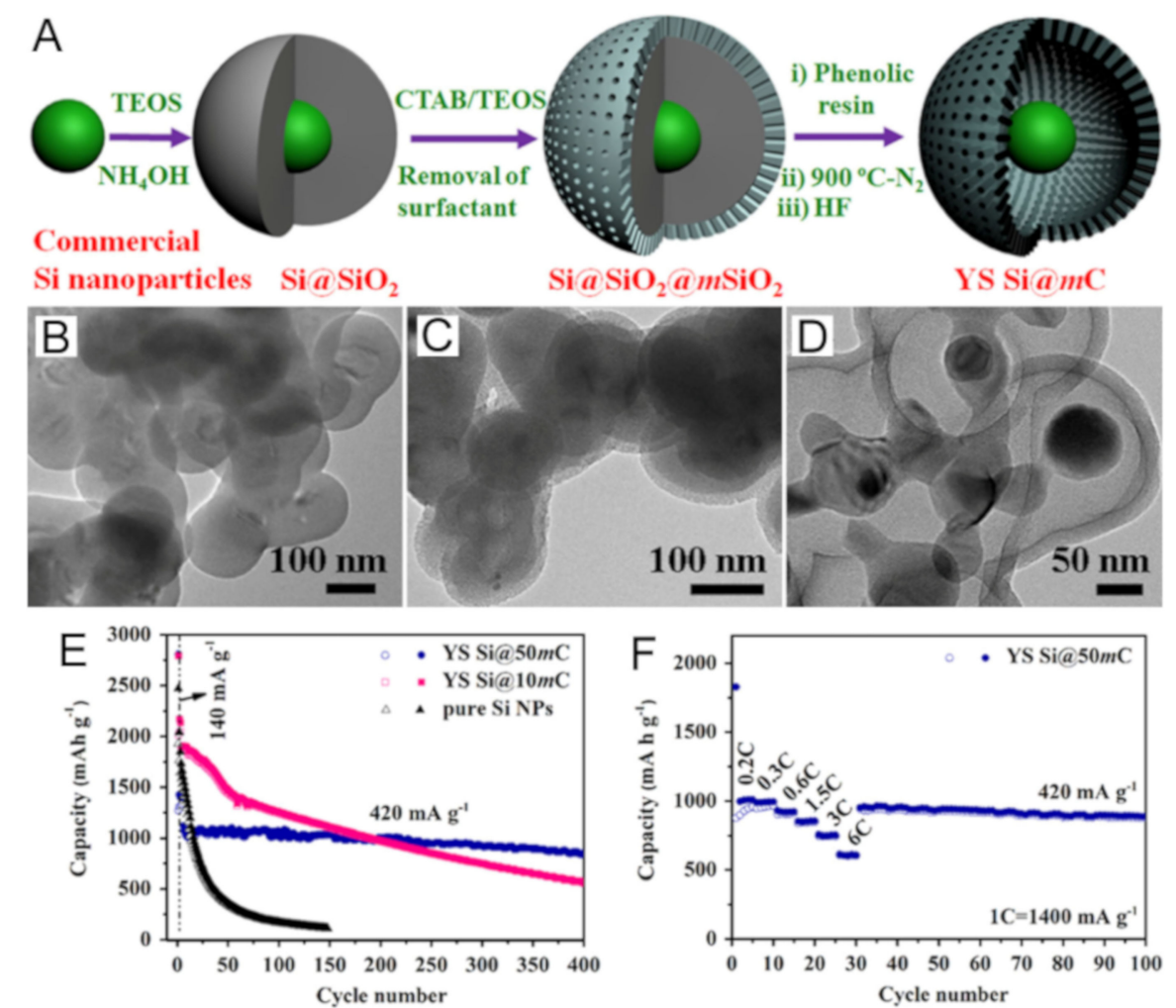

Figure 5. (A) Schematic process for the formation of the mesoporous carbon-coated silicon yolk-shell nanostructure. TEM images of (B) $\mathrm{Si}_{\mathrm{SiO}}$ core-shell nanoparticles, (C) $\mathrm{Si}_{2} \mathrm{SiO}_{2} @ \mathrm{mSiO}_{2}$ core-shell nanoparticles, and (D) $\mathrm{Si} @ \mathrm{mC}$ yolk-shell nanostructure. $\left(\mathrm{mSiO}_{2}\right.$ : mesoporous $\mathrm{SiO}_{2}, \mathrm{mC}$ : mesoporous carbon) (E) Charge-discharge cycling performance of Si nanoparticle and carbon-coated yolk-shell nanostructure electrodes. (F) Rate performance of yolk-shell nanostructure electrode. Reproduced with permission from [63]. Copyright Elsevier Ltd, 2015.

\subsubsection{Tin and Tin Oxide}

As an alloy-type anode alternative, tin is also a promising material due to its high specific capacity and low operating potential. Although tin cannot beat silicon in terms of gravimetric capacity (4200 vs. $991 \mathrm{mAh} / \mathrm{g}$, based on the formation of $\mathrm{Li}_{4.4} \mathrm{Sn}, \mathrm{Sn}+4.4 \mathrm{Li}^{+}+4.4 \mathrm{e}^{-} \leftrightarrow \mathrm{Li}_{4.4} \mathrm{Sn}$ ), it has a comparable volumetric capacity of $2020 \mathrm{mAh} / \mathrm{cm}^{3}\left(2400 \mathrm{mAh} / \mathrm{cm}^{3}\right.$ for Si) and better electrical resistivity than graphite [113]. Nevertheless, tin is prone to capacity deterioration during charging/discharging, like other alloy-type anode materials, due to huge volume change $(\sim 300 \%)$ leading to electrode pulverization, delamination from the current collector, and SEI formation. Designing pure tin anode as 
nanostructure has been suggested to alleviate the stress of tin from volume expansion [113]. Intrinsic volume change during lithiation/delithiation pushes the research towards using the buffer layer to keep tin nano-/micro-scale anode from pulverization by creating core-protected structure. Kang and co-workers have demonstrated that yolk-shell nanostructured Sn@C electrode showed better cycling stability than pure Sn powder [66]. Carbon-coated Sn microsphere was prepared by spray pyrolysis (Figure 6). Firstly, $\mathrm{SnO}_{2}-\mathrm{ZnO} @ \mathrm{C}$ microsphere (core-shell) was synthesized and, then, transformed to yolk-shell $\mathrm{Sn} @ \mathrm{C}$ microsphere by reducing $\mathrm{SnO}_{2}$ and vaporizing $\mathrm{Zn}$ (low vaporizing temp. of $\mathrm{Zn}$, $\sim 900{ }^{\circ} \mathrm{C}$ ). $\mathrm{H}_{2} / \mathrm{Ar}$ mixture gas reduced $\mathrm{SnO}_{2}$ and $\mathrm{ZnO}$ and the undecomposed PVP created a carbonized shell at $1000{ }^{\circ} \mathrm{C}$. Figure $6 \mathrm{C}$ shows the reduced Sn yolk covered with carbon shell. The yolk-shell Sn@C electrode showed initial discharge and charge capacities of 1458 and $781 \mathrm{mAh} / \mathrm{g}$ indicating an initial Coulombic efficiency of $54 \%$. In comparison, the pure tin nanopowder electrode has $75 \%$ of initial Coulombic efficiency due to a large irreversible capacity from an amorphous carbon shell in yolk-shell electrode. However, the yolk-shell Sn@C electrode showed a better long-term cycling performance in Figure 6E. The capacity retention of Sn@C electrode is $83 \%$ from the second cycle to $500^{\text {th }}$ cycle. The stable cycling is attributed to the void in yolk-shell nanostructure, in which Sn can maintain its morphology inside the carbon shell during lithiation/delithiation. The concept of Sn@C yolk-shell nanostructure was also demonstrated in the form of nanotube [67], integration with nanofiber [68,71], and core-sheath nanowire [69].

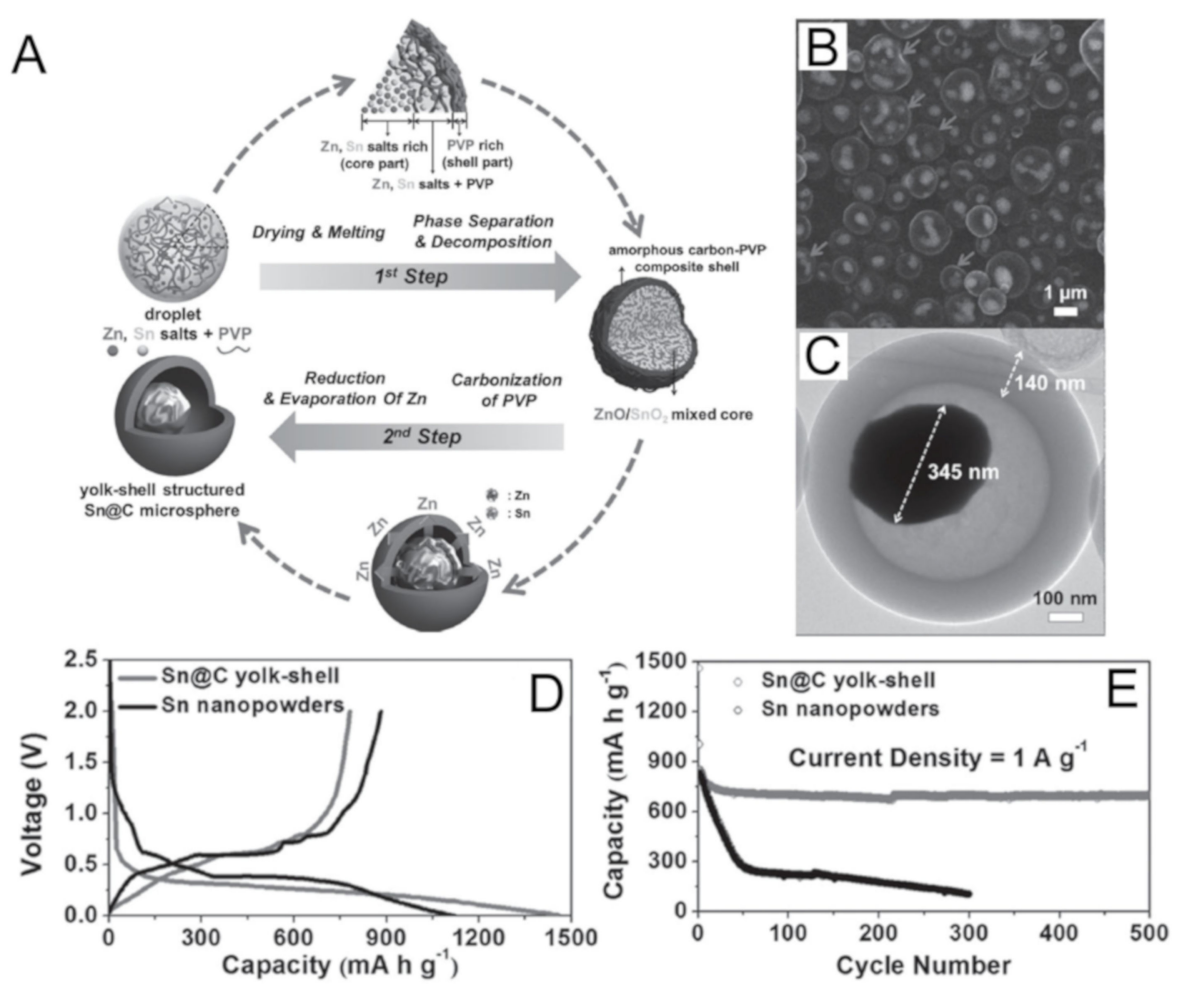

Figure 6. (A) Schematic illustration of the formation mechanism of yolk-shell Sn@C nanostructure (in the middle). SEM (B) and TEM (C) image of the yolk-shell Sn@C spheres by eliminating Zn component. (D) Initial charge and discharge profiles of tin powder and Sn@C yolk-shell electrodes. (E) Cycling performance of the two electrodes. Reproduced with permission from [66]. Copyright Wiley-VCH, 2015.

Tin oxide has the lowest operating voltages $\left(0.3\right.$ and $0.5 \mathrm{~V} \mathrm{vs.} \mathrm{Li} / \mathrm{Li}^{+}$, for discharge and charge) among other transition metal oxides. Tin oxide is also classified as alloy-type anode materials according to the following electrochemical processes: [114]

$$
\mathrm{SnO}_{2}+4 \mathrm{Li}^{+}+4 \mathrm{e}^{-} \leftrightarrow \mathrm{Sn}+2 \mathrm{Li}_{2} \mathrm{O}
$$




$$
\mathrm{Sn}+x \mathrm{Li}^{+}+x \mathrm{e}^{-} \leftrightarrow \mathrm{Li}_{x} \mathrm{Sn}(0 \leq x \leq 4.4)
$$

Thus, tin oxide is one of the alloy-type anode materials that has been investigated to design yolk-shell nanostructure for stable long-term cycling. Mostly, tin oxide nanoparticles were coated with a carbonaceous shell, followed by etching the template or buffer layer and carbonization at high temperatures. Well-controlled $\mathrm{SnO}_{2} @ \mathrm{C}$ yolk-shell nanospheres were reported by Zhao and co-workers (Figure 7) [72]. Uniform $\mathrm{SnO}_{2} @ \mathrm{C}$ nanospheres were synthesized by coating silica layer and resorcinol-formaldehyde (RF). The silica layer was etched and RF was carbonized to form hollow $\mathrm{SnO}_{2} @ \mathrm{C}$ yolk-shell nanostructure (Figure 7A). Figure 7B,C shows the SEM and TEM images of hollow $\mathrm{SnO}_{2} @ \mathrm{C}$ nanospheres after carbonization. The size of the void space and the thickness of the carbon shell can be controlled by controlling the precursors of silica and carbon. Due to the carbon shell, the first discharge/charge capacities of $\mathrm{SnO}_{2} @ \mathrm{C}$ exhibit a larger value of 2190 and $1236 \mathrm{mAh} / \mathrm{g}$ than those of pure $\mathrm{SnO}_{2}$ electrode, respectively (Figure 7D). Despite the lower first Coulombic efficiency of $\mathrm{SnO}_{2} @ \mathrm{C}(43 \%)$, the yolk-shell nanostructure shows the improved cycling performance with a high reversible capacity of $\sim 950 \mathrm{mAh} / \mathrm{g}$ after 10 cycles and $\sim 630 \mathrm{mAh} / \mathrm{g}$ after 100 cycles (Figure 7E). In contrast, the pure $\mathrm{SnO}_{2}$ electrode approaches to zero capacity after 70 cycles indicating that the carbon shell and void in yolk-shell $\mathrm{SnO}_{2} @ \mathrm{C}$ facilitate the cycling stability.

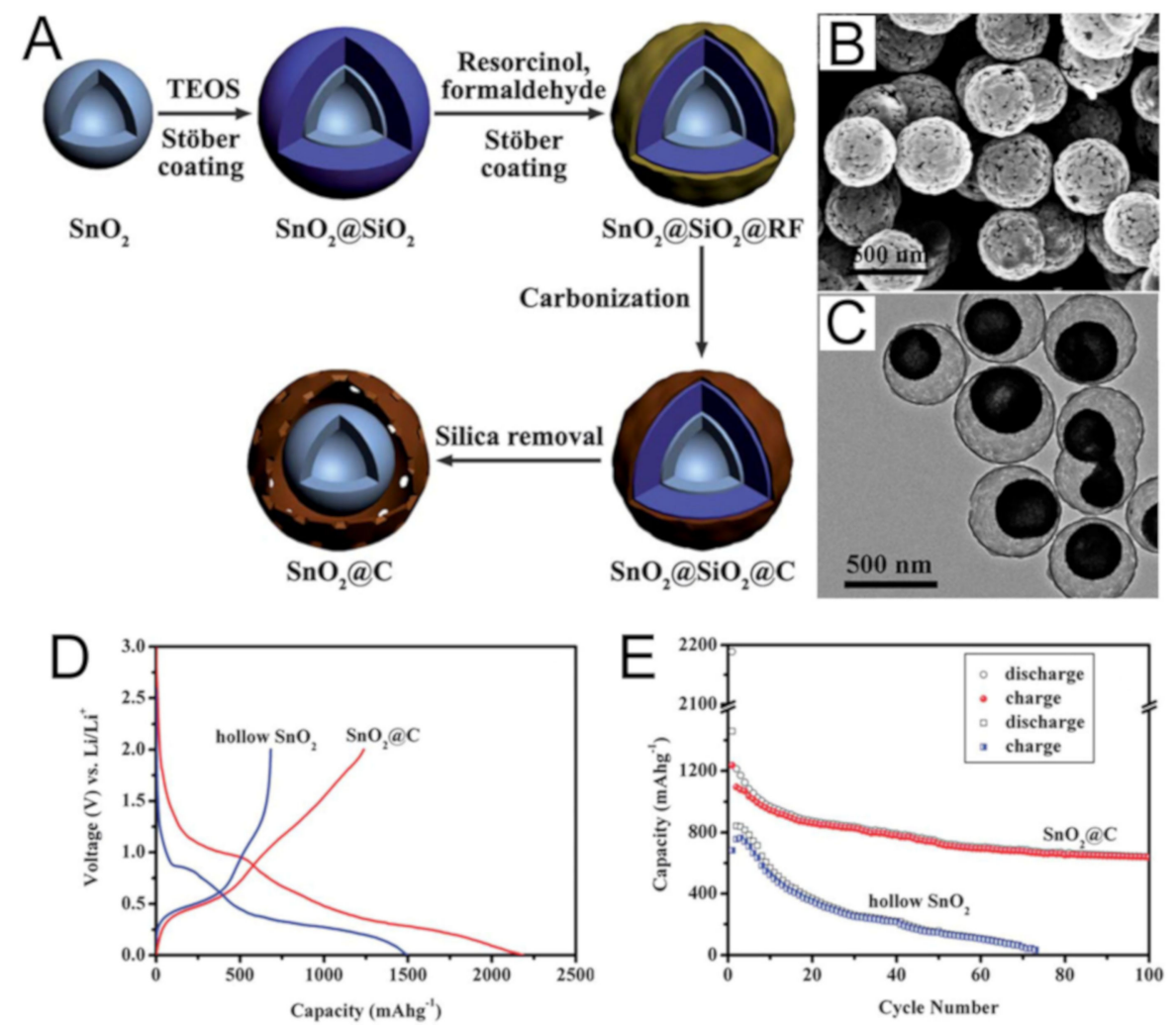

Figure 7. (A) The formation process of the $\mathrm{SnO}_{2} @ \mathrm{C}$ yolk-shell nanostructure. SEM (B) and TEM (C) images of the $\mathrm{SnO}_{2} @ \mathrm{C}$ yolk-shell nanostructures. Initial charge-discharge curves (D) and cycling performance (E) of the $\mathrm{SnO}_{2} @ \mathrm{C}$ yolk-shell nanostructure and hollow $\mathrm{SnO}_{2}$ particle electrodes. Reproduced with permission from [72]. Copyright The Royal Society of Chemistry, 2014.

\subsubsection{Aluminum}

Aluminum is another attractive alloy-type anode material owing to cheap price (\$2000/ton), high theoretical capacity $\left(2235 \mathrm{mAh} / \mathrm{g}\right.$, based on $\left.4 \mathrm{Al}+9 \mathrm{Li}^{+}+9 \mathrm{e}^{-} \leftrightarrow \mathrm{Li}_{9} \mathrm{Al}_{4}\right)$, and high electrical conductivity [115]. However, the practical performance is still suffering from relatively low capacity due to the electrode damage from the volume change $(\sim 100 \%)$ and pulverization. Even the hybrid structure of aluminum nanoparticles with carbon achieved only $900 \mathrm{mAh} / \mathrm{g}$ [116]. Instead of carbon 
shell, inorganic and mesoporous $\mathrm{TiO}_{2}$ shell was employed as a constituent of yolk-shell $\mathrm{Al} @ \mathrm{TiO}_{2}$ anode material by $\mathrm{Li}$ and co-workers [77]. The yolk-shell $\mathrm{Al} @ \mathrm{TiO}_{2}$ nanospheres were synthesized through forming $\mathrm{TiO}(\mathrm{OH})$ and etching $\mathrm{Al}_{2} \mathrm{O}_{3}$ on the surface of aluminum particles to create a void inside the shell. $\mathrm{TiO}(\mathrm{OH})$ shell is converted to anatase $\mathrm{TiO}_{2}$ by calcination at $450{ }^{\circ} \mathrm{C}$ (Figure $8 \mathrm{~A}$ ). The resultant yolk-shell $\mathrm{Al} @ \mathrm{TiO}_{2}$ nanospheres have an aluminum core $(\sim 30 \mathrm{~nm})$ and $\mathrm{TiO}_{2}$ shell $(\sim 3 \mathrm{~nm})$

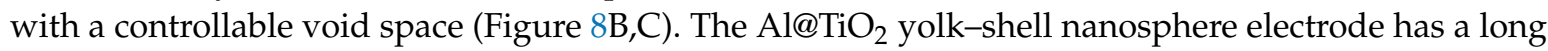
lifecycle, which maintains $~ 1100 \mathrm{mAh} / \mathrm{g}$ after 500 cycles at $1 \mathrm{C}$ rate with $93 \%$ of Coulombic efficiency (Figure 8D,E). Even at $10 \mathrm{C}$ rate, the electrode achieved a capacity of $661 \mathrm{mAh} / \mathrm{g}$ after $500 \mathrm{cycles}$. The high rate performance is attributed to the good electrical conductivity of aluminum. Compared to silicon-carbon yolk-shell electrodes, $\mathrm{Al}_{\mathrm{TiO}}$, has lower capacity at a low rate $(1 \mathrm{C})$, but exhibits higher rate performance after a long cycle. The $\mathrm{Al} @ \mathrm{TiO}_{2}$ has a few times larger specific capacity than LTO and graphite.

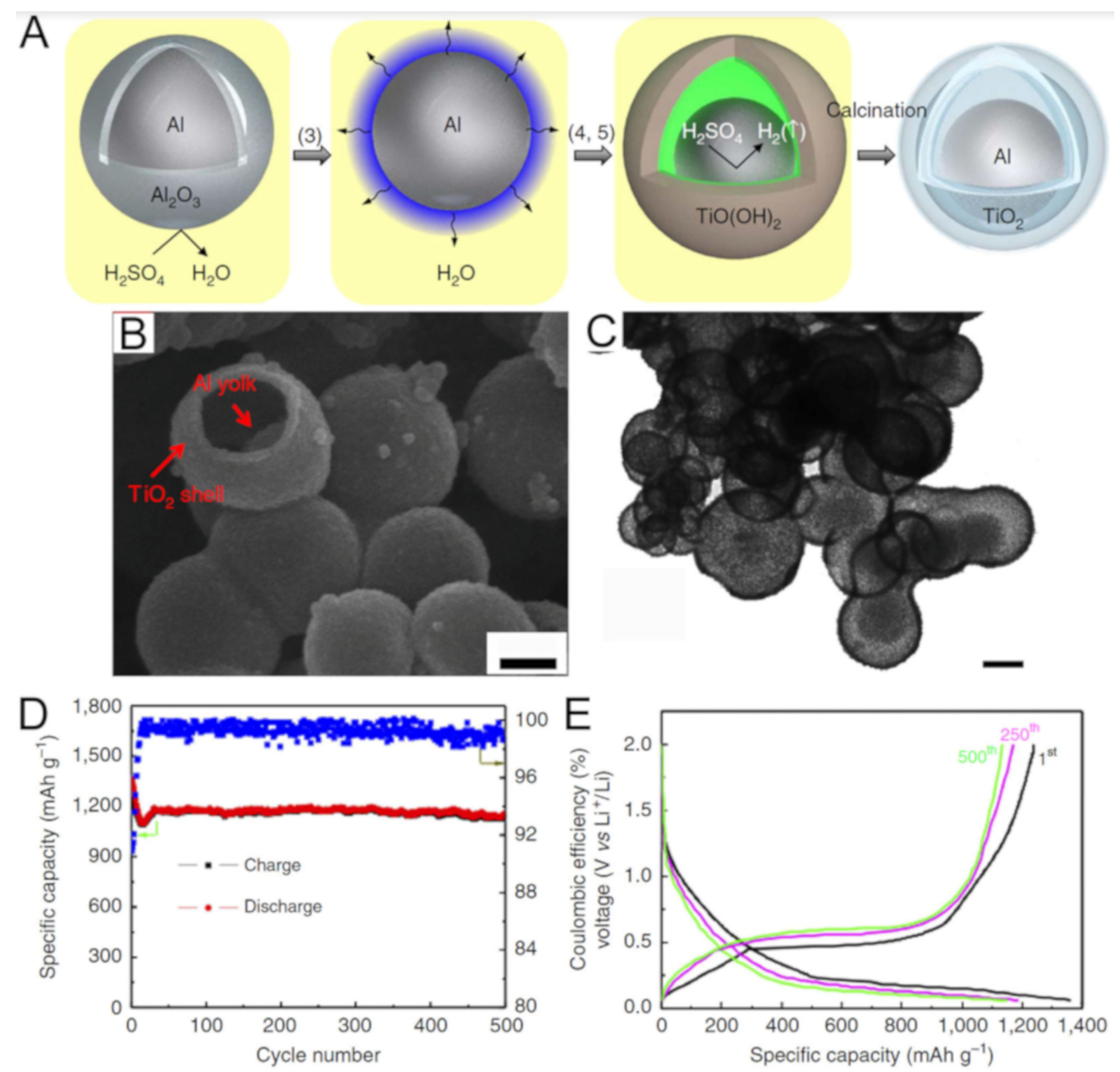

Figure 8. (A) Synthetic step of $\mathrm{Al} @ \mathrm{TiO}_{2}$ yolk-shell nanospheres. SEM (B) and TEM (C) images of yolk-shell $\mathrm{Al} @ \mathrm{TiO}_{2}$ nanostructures. (D) Cycling performance and Coulombic efficiency at $1 \mathrm{C}$ rate. Scale bars are $20 \mathrm{~nm}(\mathbf{B})$ and $10 \mathrm{~nm}(\mathbf{C})$. (E) Charge-discharge profile of the first, $250^{\text {th }}$, and $500^{\text {th }}$ cycling. Reproduced with permission from [77]. Copyright Springer Nature Publishers Ltd, 2015.

\subsection{Conversion Materials}

Conversion-based anode materials follow the electrochemical reaction mechanism to form transition metal compounds such as oxides, phosphides, sulfides, selenides and nitrides with lithium or sodium. These materials involve the reduction (oxidation) of the transition metal along with the composition (decomposition) of lithium or sodium compounds $\left(\mathrm{Li}_{x} \mathrm{X}_{y}, \mathrm{Na}_{x} \mathrm{X}_{y} ; \mathrm{X}=\mathrm{O}, \mathrm{P}, \mathrm{S}, \mathrm{Se}, \mathrm{N}\right)$. A high number of electrons in the conversion reaction of these materials can induce high reversible capacities. Nevertheless, metal oxides have some issues such as very low electrical conductivity, unstable SEI formation, and poor capacity retention due to phase segregation, volume change, and ionic/electronic 
transport [9]. Thus, as a buffer layer or conducting layer, yolk-shell nanostructure has been employed to improve electrochemical properties of conversion-type anode materials. Synthetic approaches can be classified into four mechanisms based on the step of void formation: spray pyrolysis, Ostwald ripening, etching, and thermal treatment.

Spray pyrolysis is a continuous and rapid one-pot process for fabricating micro-/nanopowder. In addition, neither template material nor etching step is necessary compared to the templating method. Various transition metal oxides can be synthesized by spray pyrolysis with high crystallinity for a few seconds. The morphologies of the yolk-shell particles prepared by spray pyrolysis were affected by the types of spray solution and temperature. The formation of carbon-metal oxide particles was formed as an intermediate product, followed by decomposition of precursors and combustion of carbon to create yolk-shell nanostructure. Thus, most yolk-shell particles synthesized by spray pyrolysis have the same composition of shells with core materials. Figure 9 shows the formation of yolk-shell NiO@NiO nanoparticle, demonstrated by Kang and co-workers [91]. A dense carbon/ $\mathrm{NiO}$ intermediate particle was formed from Ni-Sucrose droplet by the decomposition of nickel nitrate and the carbonization of sucrose. Further combustion of the intermediate particle produced core-shell carbon/NiO@NiO composite and, finally, yolk-shell $\mathrm{NiO} @ \mathrm{NiO}$ particles after carbon combustion. For a comparative study, the electrochemical measurements were performed with both the yolk-shell $\mathrm{NiO} @ \mathrm{NiO}$ and single-crystalline cubic $\mathrm{NiO}$ particles. Figure $9 \mathrm{~B}$ shows the cycling performances of the two electrodes at $1 \mathrm{C}$. Whereas the cubic $\mathrm{NiO}$ electrode showed no increase in discharge capacities after 150 cycles, the yolk-shell electrode experienced capacity increase after 60 cycles. This is attributed to the formation of a gel-like film of the transition metal oxides due to small grain and size [117]. The rate performance of the yolk-shell NiO@NiO is slightly better than the pure cubic particle (Figure 9C). The simple and self-templating spray pyrolysis have been applied to fabricate various metal oxides yolk-shell nanostructure; $\mathrm{Co}_{3} \mathrm{O}_{4}$ [78], $\mathrm{CoMn}_{2} \mathrm{O}_{4}$ [79], $\mathrm{Fe}_{2} \mathrm{O}_{3}$ [83], $\mathrm{NiMoO}_{4}$ [92], $\mathrm{ZnCo}_{2} \mathrm{O}_{4}$ [97], $\mathrm{ZnFe}_{2} \mathrm{O}_{4}$ [98], $\mathrm{ZnO} / \mathrm{Mn}_{3} \mathrm{O}_{4}$ [99], $\mathrm{MoSe}_{2}$ [102] and mixed metal oxides [118]. Furthermore, chemical transformation can produce transition metal sulfide yolk-shell nanostructure by an anion exchange. The prepared yolk-shell $\mathrm{SnO}_{2}$ particles can be converted into yolk-shell $\mathrm{SnS}$ particles through sulfidation [103].
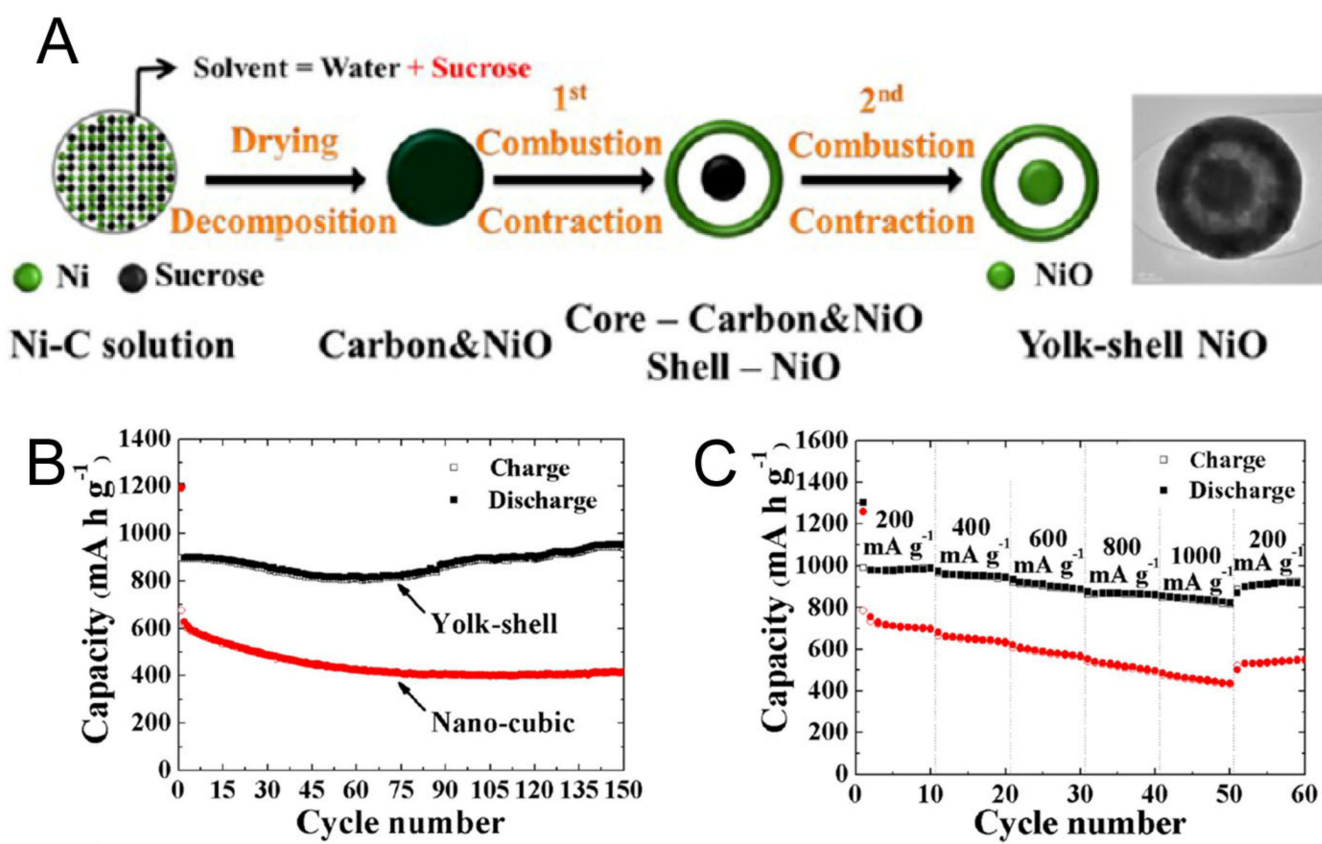

Yolk-shell NiO

Figure 9. (A) Schematic diagram of the yolk-shell $\mathrm{NiO}$ nanosphere by spray pyrolysis. Cycling performance $(\mathbf{B})$ and rate performance $(\mathbf{C})$ of the yolk-shell and single crystalline cubic $\mathrm{NiO}$ nanopowder electrodes in the voltage range of 0.001-3 V. Reproduced with permission from [91]. Copyright American Chemical Society, 2014. 
Ostwald ripening is another approach to form yolk-shell nanostructure without template material. Generally, a solid material starts to dissolve or evacuate and a shell is formed on the surface of the solid core at the expense of dissolving the core material due to the high surface energy. Figure 10A shows the sequential steps of the formation of the yolk-shell $\mathrm{MoO}_{2}$ microsphere through Ostwald ripening. From the SEM images, the smooth microsphere starts to form small nanoparticles on the surface and the growth of the shell, followed by creating void inside. The resultant yolk-shell $\mathrm{MoO}_{2}$ is crystalline with monoclinic $\mathrm{MoO}_{2}$ phase. The rate performance and cycling stability of the yolk-shell $\mathrm{MoO}_{2}$ electrode is reasonable, which has 714 and $450 \mathrm{mAh} / \mathrm{g}$ at $0.5 \mathrm{~A} / \mathrm{g}$ and $2 \mathrm{~A} / \mathrm{g}$, respectively (Figure 10B,C). This enhanced electrochemical performance of the $\mathrm{MoO}_{2}$ microspheres can be originated from the better kinetics of the yolk-shell nature, which facilitates the electrolyte to transport Li ions during intercalation/deintercalation. Other anode materials structured as yolk-shell are also investigated by Ostwald ripening; $\mathrm{TiO}_{2}$ [106], $\mathrm{V}_{2} \mathrm{O}_{3}$ [94], $\mathrm{ZnO}$ [95], $\mathrm{ZnO@} \mathrm{ZnO} / \mathrm{NiO}$ [96], $\mathrm{CoS}_{2}$ [100].
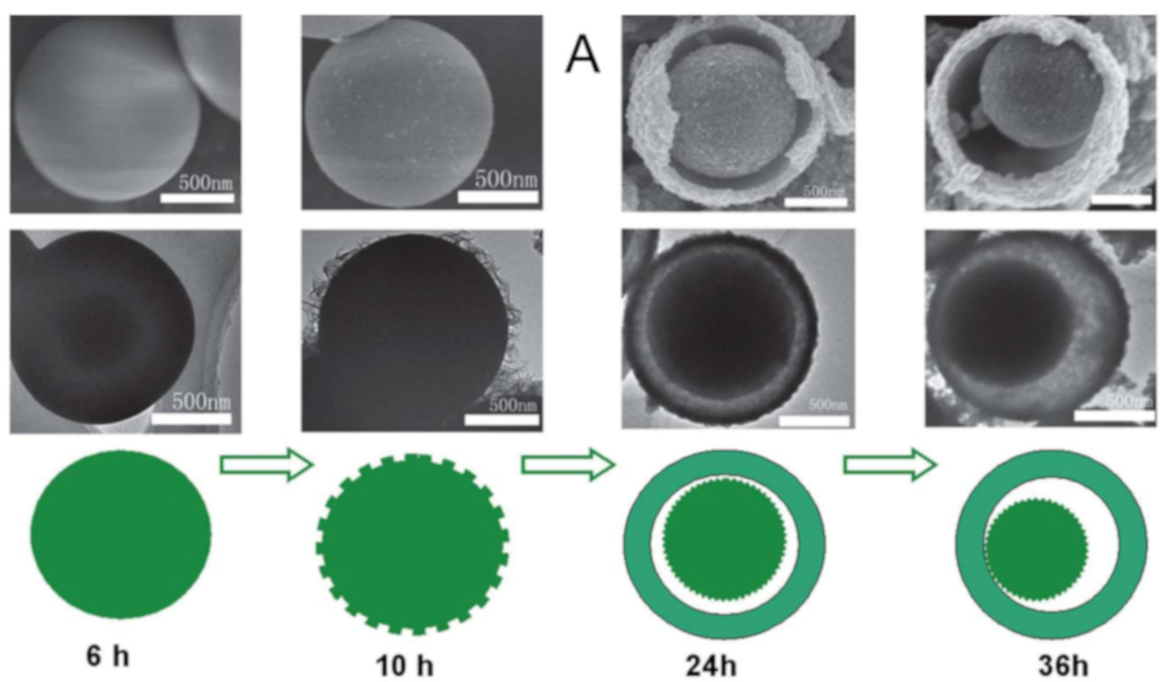

$6 \mathrm{~h}$

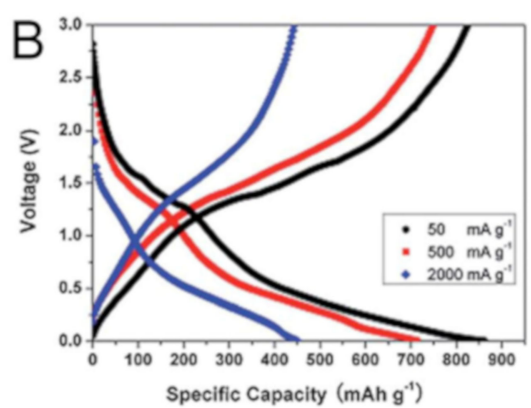

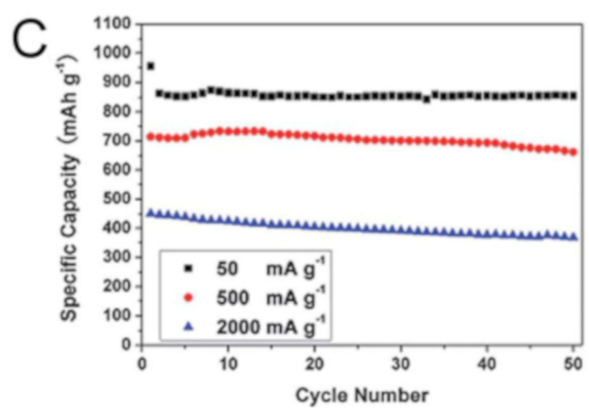

Figure 10. (A) Schematic illustration of the formation process of yolk-shell $\mathrm{MoO}_{2}$ spheres by Ostwald ripening and the corresponding SEM and TEM images. (B) Charge-discharge voltage profiles of the yolk-shelled $\mathrm{MoO}_{2}$ electrode at different current densities. (C) Cycling performance. Reproduced with permission from [87]. Copyright The Royal Society of Chemistry, 2013.

Templating approach towards yolk-shell nanostructure design is beneficial in a way that heterogeneous shell materials can be coated around the core, followed by the elimination of unwanted materials. One of the most historic methods to use template material for yolk-shell nanostructure is coating the first layer and then etching that layer after coating the second layer. Most Si@C yolk-shell nanostructures were achieved by the etching method. Likewise, metal oxides can also be produced as a yolk-shell particle through the etching method. An iron oxid@carbon yolk-shell nanostructure was designed through etching by $\mathrm{Yu}$ and co-workers [82]. $\alpha$ - $\mathrm{Fe}_{2} \mathrm{O}_{3}$ nanocrystals were coated with a conformal silica layer by controlled hydrolysis and condensation of TEOS to form $\alpha-\mathrm{Fe}_{2} \mathrm{O}_{3} @ \mathrm{SiO}_{2}$ (Figure 11A). Poly-dopamine was coated on the surface, followed by carbonization 
to obtain $\mathrm{FeO}_{x} @ \mathrm{SiO}_{2} @ \mathrm{C}$ nanoparticles. Basic solution was used to remove the sacrificial silica layer. The resultant $\mathrm{FeO}_{x} @ \mathrm{C}$ yolk-shell nanoparticles have a controllable void size depending on the thickness of the silica layer (Figure 11B-E). The optimal void size of $\mathrm{FeO}_{x} @ \mathrm{C}$ yolk-shell anode material was investigated by performing electrochemical tests. Figure $11 \mathrm{~F}$ shows the cycling performance of the yolk-shell electrode indicating that $\mathrm{FeO}_{x} @ \mathrm{C}-2$ (silica layer thickness: 15 20 nm) achieved the highest and stable long-term capacity value, compared to the thinner $(\sim 9 \mathrm{~nm})$ and thicker layer $(\sim 45 \mathrm{~nm})$. $\mathrm{FeO}_{x} @ \mathrm{C}-2$ electrode delivers a high capacity of $820 \mathrm{mAh} / \mathrm{g}$ at $0.2 \mathrm{C}$ and $\sim 380 \mathrm{mAh} / \mathrm{g}$ at $4 \mathrm{C}$, which is comparable to the theoretical capacity of graphite (Figure 11G). FeO $@$ C-2 outperforms the other $\mathrm{FeO}_{x} @ \mathrm{C}$ electrodes since the small void space was found to rupture the carbon shell after cycling, which is indicative of insufficient space for volume expansion. However, in the case of the thicker $\mathrm{FeO}_{x} @ \mathrm{C}$ nanoparticles, volumetric capacity becomes lower. Templating methods through etching has produced other metal or metal oxide yolk-shell nanostructures; $\mathrm{Fe}_{2} \mathrm{O}_{3} @ \mathrm{C}$ [80], $\mathrm{Fe}_{3} \mathrm{O}_{4} @ \mathrm{C}$ [81], $\mathrm{MnO}_{2} @ \mathrm{C}$ [86], Ni@graphene [89].

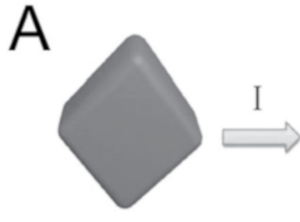
$\mathrm{a}-\mathrm{Fe}_{2} \mathrm{O}_{3}$
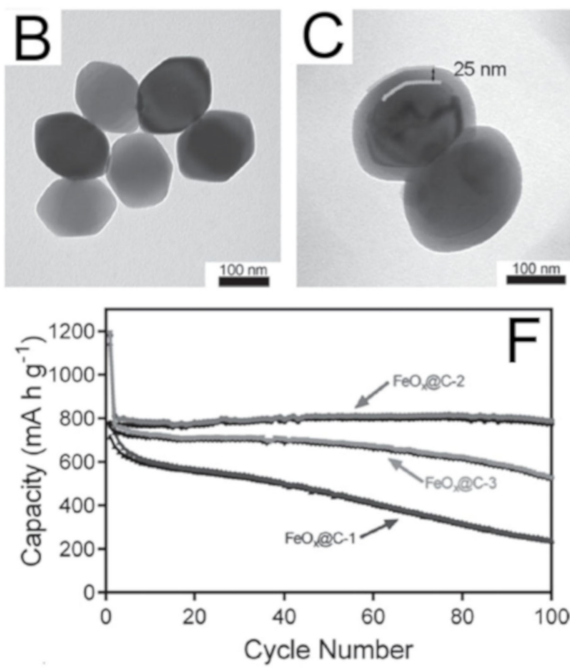
$\alpha-\mathrm{Fe}_{2} \mathrm{O}_{3} @ \mathrm{SiO}_{2}$

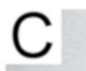

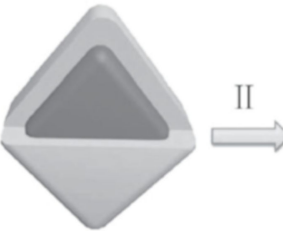
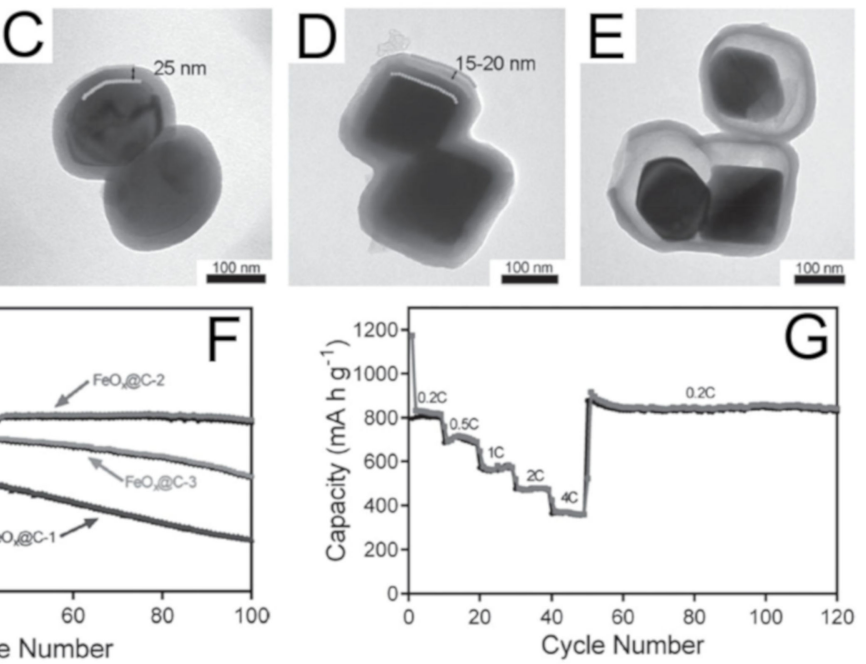

Figure 11. (A) Schematic illustration showing the formation of $\mathrm{FeO}_{x} @ \mathrm{C}$ yolk-shell nanostructure. (B-E) TEM images corresponding to each step in (A): $\alpha-\mathrm{Fe}_{2} \mathrm{O}_{3} \rightarrow \alpha-\mathrm{Fe}_{2} \mathrm{O}_{3} @ \mathrm{SiO}_{2} \rightarrow \mathrm{FeO}_{x} @ \mathrm{SiO}_{2} @ \mathrm{C} \rightarrow$ $\mathrm{FeO}_{x} @ \mathrm{C}$. (F) Cycling capacity of $\mathrm{FeO}_{x} @ \mathrm{C}$ yolk-shell nanostructures at $0.2 \mathrm{C}$. (G) Rate performance of $\mathrm{FeO}_{x} @ \mathrm{C}-2$. Reproduced with permission from [82]. Copyright Wiley-VCH, 2014.

Yolk-shell nanostructures containing carbon shell can be obtained by thermal treatment to carbonize a carbonaceous shell material, followed by contraction of core materials to create a void. $\mathrm{Fe}_{3} \mathrm{O}_{4} / \mathrm{Fe}_{3} \mathrm{C} @ \mathrm{C}$ yolk-shell nanospindles were synthesized by Guo and co-workers. Firstly, uniform $\alpha-\mathrm{Fe}_{2} \mathrm{O}_{3}$ nanospindle were prepared by hydrothermal reaction and coated with a conformal RF resin layer to form $\alpha-\mathrm{Fe}_{2} \mathrm{O}_{3} @ \mathrm{RF}$ core-shell structure (Figure 12A). Thermal treatment at $550{ }^{\circ} \mathrm{C}$ produced $\mathrm{Fe}_{3} \mathrm{O}_{4} / \mathrm{Fe}_{3} \mathrm{C} @ \mathrm{C}$ yolk-shell nanostructure by escaping the core from the carbon shell (Figure 12B,C). Interestingly, only $\mathrm{Fe}_{3} \mathrm{O}_{4} @ \mathrm{C}$ core-shell nanospindles were obtained when RF was replaced by another carbonaceous material (glucose). The electrochemical performance of $\mathrm{Fe}_{3} \mathrm{O}_{4} / \mathrm{Fe}_{3} \mathrm{C} @ \mathrm{C}$ yolk-shell nanospindles were compared with pure $\mathrm{Fe}_{3} \mathrm{O}_{4}$ nanoparticle and $\mathrm{Fe}_{3} \mathrm{O}_{4} @ \mathrm{C}$ core-shell nanospindle in Figure 12D,E. The $\mathrm{Fe}_{3} \mathrm{O}_{4} / \mathrm{Fe}_{3} \mathrm{C} @ \mathrm{C}$ yolk-shell nanospindles outperforms the other two electrodes in terms of rate capability and long-term cycling stability. The increasing capacity of $\mathrm{Fe}_{3} \mathrm{O}_{4} / \mathrm{Fe}_{3} \mathrm{C} @ \mathrm{C}$ 
yolk-shell nanospindles in Figure 12D can be found in metal oxide electrodes [119,120]. Metal oxide yolk-shell nanostructures synthesized by thermal treatment include $\mathrm{Cr}_{2} \mathrm{O}_{3} @ \mathrm{TiO}_{2}$ [47], $\mathrm{Fe}_{3} \mathrm{O}_{4} @ \mathrm{TiO}_{2}$ [84], $\mathrm{FeO}_{x} @$ graphene [44], $\mathrm{MnO}_{2} @ \mathrm{C}$ [85], $\mathrm{NiO} @ \mathrm{C}$ [88] and $\mathrm{TiO}_{2} @ \mathrm{C}$ [108].

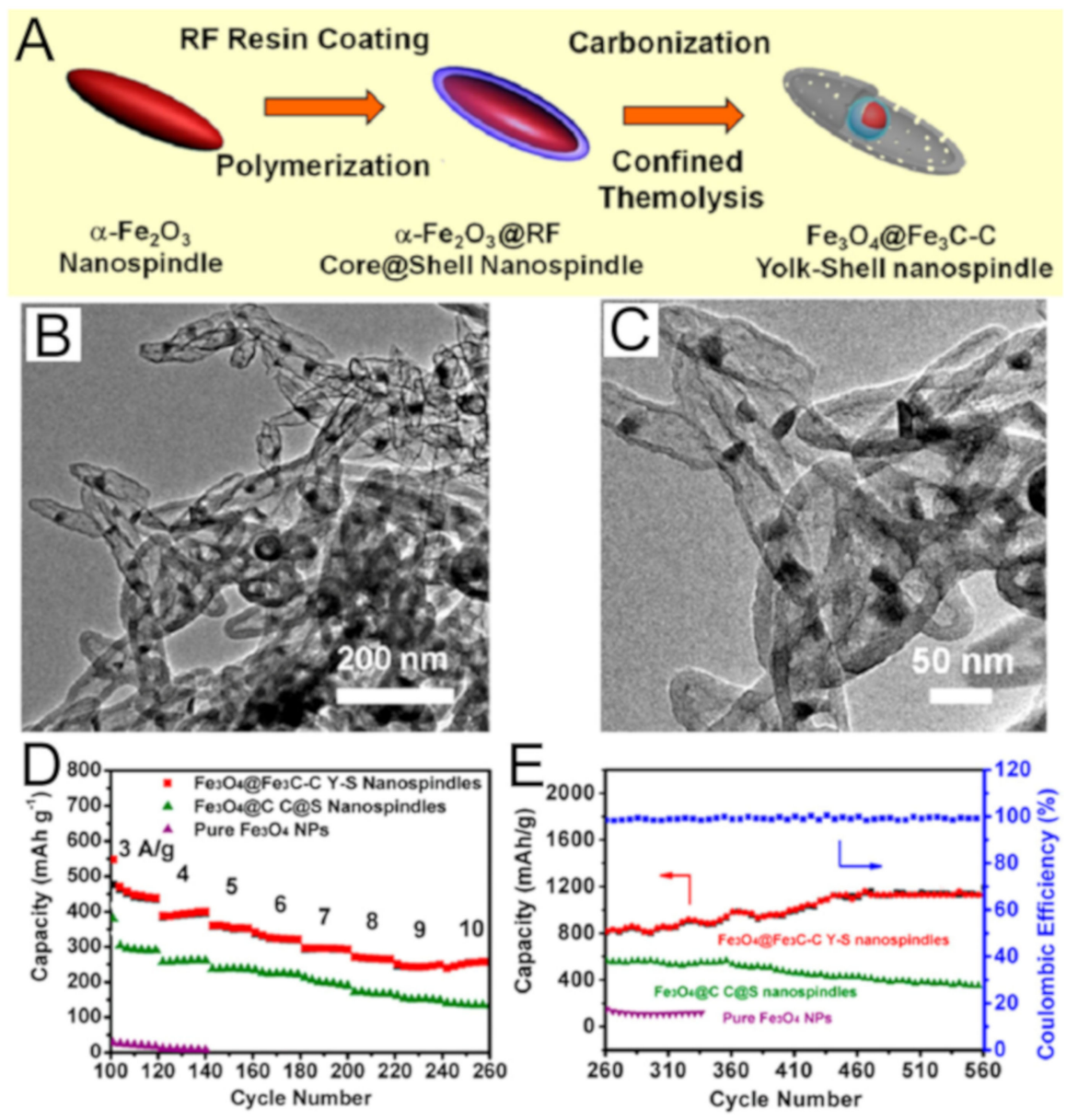

Figure 12. (A) Scheme showing the formation of $\mathrm{Fe}_{3} \mathrm{O}_{4} @ \mathrm{Fe}_{3} \mathrm{C}-\mathrm{C}$ yolk-shell nanostructure. (B,C) TEM images of $\mathrm{Fe}_{3} \mathrm{O}_{4} @ \mathrm{Fe}_{3} \mathrm{C}-\mathrm{C}$. (D) Capacity retention of the yolk-shell electrode, $\mathrm{Fe}_{3} \mathrm{O}_{4} @ \mathrm{C}$ core-shell electrode, and pure $\mathrm{Fe}_{3} \mathrm{O}_{4}$ nanoparticle electrode. (E) Cycling performance of the three electrodes and Coulombic efficiency of the yolk-shell electrode. Reproduced with permission from [47]. Copyright American Chemical Society, 2015.

\section{Conclusions and Outlook}

In this review, the yolk-shell nanostructures are covered in terms of designing strategies and applications in lithium and sodium battery anode materials. Compared to the conventional core-shell structure, the hollow shell containing the movable core possesses unique morphological features bringing low density, large surface area, and great loading capacity. Typically, the building-up of yolk-shell nanostructures can be classified into templating and self-templating approaches according to the use of the sacrificial layer and the necessity of the removal process. Templating methods usually exploit rigid or soft materials as sacrificial materials such as $\mathrm{SiO}_{2}$, carbon, metal, metal oxides, oligomers, and vesicles. While the templating approaches are straightforward due to the role of an additional layer, the self-templating methods cover a wide range of synthetic strategies such as galvanic replacement, Kirkendall effect, Ostwald ripening, partial removal of core, core injection, core contraction, surface-protected etching, and so on. The yolk-shell nanostructured materials have the potential for battery anode due to their morphological features relieving volume expansion and facilitating rapid diffusion with electron transportation. These superior merits of yolk-shell nanostructured anodes were demonstrated from the many reports on the improvement of Li and 
Na storage performance with high specific capacity, rate capability, and stable long-term cyclability. Nevertheless, further study is needed to focus on developing advanced morphologies for more precise control over the shape and function. In addition, the environmentally-friendly etching or dissolution process should be explored because the usual dissolution solvents like hydrofluoric acid are very harmful. Since sodium ions are larger than lithium ions, it is also required to find suitable materials with appropriate morphologies for the reasonable volume expansion ratio and high specific capacity. Definitely, the yolk-shell nanostructures with tailorable inner space are promising for improving battery performance in the near future only if a commercially available process is set up.

Funding: This research was funded by Basic Science Research Program through the National Research Foundation of Korea (NRF) funded by the Ministry of Education (No. 2017R1D1A1B030274) and Korea Institute of Industrial Technology (No. EO20016).

Conflicts of Interest: The author declares no conflict of interest.

\section{References}

1. Tang, Y.; Zhang, Y.; Li, W.; Ma, B.; Chen, X. Rational material design for ultrafast rechargeable lithium-ion batteries. Chem. Soc. Rev. 2015, 44, 5926-5940. [CrossRef] [PubMed]

2. Goriparti, S.; Miele, E.; De Angelis, F.; Di Fabrizio, E.; Proietti Zaccaria, R.; Capiglia, C. Review on recent progress of nanostructured anode materials for Li-ion batteries. J. Power Sources 2014, 257, 421-443. [CrossRef]

3. Bai, L.; Fang, F.; Zhao, Y.; Liu, Y.; Li, J.; Huang, G.; Sun, H. A sandwich structure of mesoporous anatase $\mathrm{TiO}_{2}$ sheets and reduced graphene oxide and its application as lithium-ion battery electrodes. RSC Adv. 2014, 4, 43039-43046. [CrossRef]

4. Luo, W.; Shen, F.; Bommier, C.; Zhu, H.; Ji, X.; Hu, L. Na-Ion Battery Anodes: Materials and Electrochemistry. Acc. Chem. Res. 2016, 49, 231-240. [CrossRef]

5. Chan, C.K.; Peng, H.; Liu, G.; McIlwrath, K.; Zhang, X.F.; Huggins, R.A.; Cui, Y. High-performance lithium battery anodes using silicon nanowires. Nat. Nanotechnol. 2008, 3, 31-35. [CrossRef]

6. Oumellal, Y.; Delpuech, N.; Mazouzi, D.; Dupre, N.; Gaubicher, J.; Moreau, P.; Soudan, P.; Lestriez, B.; Guyomard, D. The failure mechanism of nano-sized Si-based negative electrodes for lithium ion batteries. J. Mater. Chem. 2011, 21, 6201-6208. [CrossRef]

7. Dang, H.X.; Klavetter, K.C.; Meyerson, M.L.; Heller, A.; Mullins, C.B. Tin microparticles for a lithium ion battery anode with enhanced cycling stability and efficiency derived from Se-doping. J. Mater. Chem. A 2015, 3, 13500-13506. [CrossRef]

8. Liu, Y.; Zhang, S.; Zhu, T. Germanium-Based Electrode Materials for Lithium-Ion Batteries. ChemElectroChem 2014, 1, 706-713. [CrossRef]

9. Wu, H.B.; Chen, J.S.; Hng, H.H.; Wen Lou, X. Nanostructured metal oxide-based materials as advanced anodes for lithium-ion batteries. Nanoscale 2012, 4, 2526-2542. [CrossRef]

10. Wang, X.; Chen, D.; Yang, Z.; Zhang, X.; Wang, C.; Chen, J.; Zhang, X.; Xue, M. Novel Metal Chalcogenide SnSSe as a High-Capacity Anode for Sodium-Ion Batteries. Adv. Mater. 2016, 28, 8645-8650. [CrossRef]

11. Wang, X.; Kim, H.-M.; Xiao, Y.; Sun, Y.-K. Nanostructured metal phosphide-based materials for electrochemical energy storage. J. Mater. Chem. A 2016, 4, 14915-14931. [CrossRef]

12. Balogun, M.-S.; Qiu, W.; Wang, W.; Fang, P.; Lu, X.; Tong, Y. Recent advances in metal nitrides as high-performance electrode materials for energy storage devices. J. Mater. Chem. A 2015, 3, 1364-1387. [CrossRef]

13. Cho, J.S.; Lee, S.Y.; Kang, Y.C. First Introduction of $\mathrm{NiSe}_{2}$ to Anode Material for Sodium-Ion Batteries: A Hybrid of Graphene-Wrapped NiSe2/C Porous Nanofiber. Sci. Rep. 2016, 6, 23338. [CrossRef] [PubMed]

14. Lai, C.-H.; Lu, M.-Y.; Chen, L.-J. Metal sulfide nanostructures: Synthesis, properties and applications in energy conversion and storage. J. Mater. Chem. 2012, 22, 19-30. [CrossRef]

15. Zuo, X.; Zhu, J.; Müller-Buschbaum, P.; Cheng, Y.-J. Silicon based lithium-ion battery anodes: A chronicle perspective review. Nano Energy 2017, 31, 113-143. [CrossRef]

16. Zhao, Y.; Wang, L.P.; Sougrati, M.T.; Feng, Z.; Leconte, Y.; Fisher, A.; Srinivasan, M.; Xu, Z. A Review on Design Strategies for Carbon Based Metal Oxides and Sulfides Nanocomposites for High Performance Li and Na Ion Battery Anodes. Adv. Energy Mater. 2017, 7, 1601424. [CrossRef] 
17. Xiao, X.; Zhou, W.; Kim, Y.; Ryu, I.; Gu, M.; Wang, C.; Liu, G.; Liu, Z.; Gao, H. Regulated Breathing Effect of Silicon Negative Electrode for Dramatically Enhanced Performance of Li-Ion Battery. Adv. Funct. Mater. 2015, 25, 1426-1433. [CrossRef]

18. Liu, N.; Wu, H.; McDowell, M.T.; Yao, Y.; Wang, C.; Cui, Y. A Yolk-Shell Design for Stabilized and Scalable Li-Ion Battery Alloy Anodes. Nano Lett. 2012, 12, 3315-3321. [CrossRef]

19. Zhang, L.; Rajagopalan, R.; Guo, H.; Hu, X.; Dou, S.; Liu, H. A Green and Facile Way to Prepare Granadilla-Like Silicon-Based Anode Materials for Li-Ion Batteries. Adv. Funct. Mater. 2016, 26, 440-446. [CrossRef]

20. Khalifa, H.; El-Safty, S.A.; Reda, A.; Elmarakbi, A.; Metawa, H.; Shenashen, M.A. Multifaceted geometric 3D mesopolytope cathodes and its directional transport gates for superscalable LIB models. Appl. Mater. Today 2020, 19, 100590. [CrossRef]

21. Chen, H.; Qi, B.; Moore, T.; Wang, F.; Colvin, D.C.; Sanjeewa, L.D.; Gore, J.C.; Hwu, S.-J.; Mefford, O.T.; Alexis, F.; et al. Multifunctional Yolk-in-Shell Nanoparticles for $\mathrm{pH}$-triggered Drug Release and Imaging. Small 2014, 10, 3364-3370. [CrossRef] [PubMed]

22. Li, X.; Zhou, X.; Guo, H.; Wang, C.; Liu, J.; Sun, P.; Liu, F.; Lu, G. Design of Au@ZnO Yolk-Shell Nanospheres with Enhanced Gas Sensing Properties. ACS Appl. Mater. Interfaces 2014, 6, 18661-18667. [CrossRef] [PubMed]

23. Cui, Z.-M.; Chen, Z.; Cao, C.-Y.; Jiang, L.; Song, W.-G. A yolk-shell structured $\mathrm{Fe}_{2} \mathrm{O}_{3} @$ mesoporous $\mathrm{SiO}_{2}$ nanoreactor for enhanced activity as a Fenton catalyst in total oxidation of dyes. Chem. Commun. 2013, 49, 2332-2334. [CrossRef] [PubMed]

24. Park, J.H.; Kim, D.I.; Hong, S.G.; Seo, H.; Kim, J.; Moon, G.D.; Hyun, D.C. Poly(E-caprolactone) (PCL) Hollow Nanoparticles with Surface Sealability and On-Demand Pore Generability for Easy Loading and NIR Light-Triggered Release of Drug. Pharmaceutics 2019, 11, 528. [CrossRef]

25. Wu, S.; Dzubiella, J.; Kaiser, J.; Drechsler, M.; Guo, X.; Ballauff, M.; Lu, Y. Thermosensitive Au-PNIPA Yolk-Shell Nanoparticles with Tunable Selectivity for Catalysis. Angew. Chem. Int. Ed. 2012, 51, 2229-2233. [CrossRef]

26. Yang, Y.; Liu, X.; Li, X.; Zhao, J.; Bai, S.; Liu, J.; Yang, Q. A Yolk-Shell Nanoreactor with a Basic Core and an Acidic Shell for Cascade Reactions. Angew. Chem. Int. Ed. 2012, 51, 9164-9168. [CrossRef]

27. Yang, P.; Luo, X.; Wang, S.; Wang, F.; Tang, C.; Wang, C. Biodegradable yolk-shell microspheres for ultrasound/MR dual-modality imaging and controlled drug delivery. Colloids Surf. B: Biointerfaces 2017, 151, 333-343. [CrossRef]

28. Liu, J.; Liu, Y.; Bu, W.; Bu, J.; Sun, Y.; Du, J.; Shi, J. Ultrasensitive Nanosensors Based on Upconversion Nanoparticles for Selective Hypoxia Imaging in Vivo upon Near-Infrared Excitation. J. Am. Chem. Soc. 2014, 136, 9701-9709. [CrossRef]

29. Shenashen, M.A.; Akhtar, N.; Selim, M.M.; Morsy, W.M.; Yamaguchi, H.; Kawada, S.; Alhamid, A.A.; Ohashi, N.; Ichinose, I.; Alamoudi, A.S.; et al. Effective, Low-Cost Recovery of Toxic Arsenate Anions from Water by Using Hollow-Sphere Geode Traps. Chem. Asian J. 2017, 12, 1952-1964. [CrossRef]

30. Soliman, A.-A.E.; Shenashen, M.A.; El-Sewify, I.M.; Taha, G.M.; El-Taher, M.A.; Yamaguchi, H.; Alamoudi, A.S.; Selim, M.M.; El-Safty, S.A. Mesoporous Organic-Inorganic Core-Shell Necklace Cages for Potentially Capturing $\mathrm{Cd}^{2+}$ Ions from Water Sources. ChemistrySelect 2017, 2, 6135-6142. [CrossRef]

31. Lee, I.; Joo, J.B.; Yin, Y.; Zaera, F. Au@Void@TiO 2 yolk-shell nanostructures as catalysts for the promotion of oxidation reactions at cryogenic temperatures. Surf. Sci. 2016, 648, 150-155. [CrossRef]

32. Lin, L.-S.; Song, J.; Yang, H.-H.; Chen, X. Yolk-Shell Nanostructures: Design, Synthesis, and Biomedical Applications. Adv. Mater. 2018, 30, 1704639. [CrossRef] [PubMed]

33. Selim, M.S.; El-Safty, S.A.; Azzam, A.M.; Shenashen, M.A.; El-Sockary, M.A.; Abo Elenien, O.M. Superhydrophobic Silicone/ $/ \mathrm{TiO}_{2}-\mathrm{SiO}_{2}$ Nanorod-like Composites for Marine Fouling Release Coatings. ChemistrySelect 2019, 4, 3395-3407. [CrossRef]

34. Chen, Y.; Chen, H.; Guo, L.; He, Q.; Chen, F.; Zhou, J.; Feng, J.; Shi, J. Hollow/Rattle-Type Mesoporous Nanostructures by a Structural Difference-Based Selective Etching Strategy. ACS Nano 2010, 4, 529-539. [CrossRef] [PubMed]

35. Moon, G.D.; Jeong, U. Decoration of the Interior Surface of Hollow Spherical Silica Colloids with Pt Nanoparticles. Chem. Mater. 2008, 20, 3003-3007. [CrossRef]

36. Sun, Y.; Wiley, B.; Li, Z.-Y.; Xia, Y. Synthesis and Optical Properties of Nanorattles and Multiple-Walled Nanoshells/Nanotubes Made of Metal Alloys. J. Am. Chem. Soc. 2004, 126, 9399-9406. [CrossRef] [PubMed] 
37. Da Silva, A.G.M.; Rodrigues, T.S.; Correia, V.G.; Alves, T.V.; Alves, R.S.; Ando, R.A.; Ornellas, F.R.; Wang, J.; Andrade, L.H.; Camargo, P.H.C. Plasmonic Nanorattles as Next-Generation Catalysts for Surface Plasmon Resonance-Mediated Oxidations Promoted by Activated Oxygen. Angew. Chem. Int. Ed. 2016, 55, 7111-7115. [CrossRef]

38. Shevchenko, E.V.; Bodnarchuk, M.I.; Kovalenko, M.V.; Talapin, D.V.; Smith, R.K.; Aloni, S.; Heiss, W.; Alivisatos, A.P. Gold/Iron Oxide Core/Hollow-Shell Nanoparticles. Adv. Mater. 2008, 20, 4323-4329. [CrossRef]

39. Cao, L.; Chen, D.; Caruso, R.A. Surface-Metastable Phase-Initiated Seeding and Ostwald Ripening: A Facile Fluorine-Free Process towards Spherical Fluffy Core/Shell, Yolk/Shell, and Hollow Anatase Nanostructures. Angew. Chem. Int. Ed. 2013, 52, 10986-10991. [CrossRef]

40. Liu, Z.; Yu, X.-Y.; Paik, U. Etching-in-a-Box: A Novel Strategy to Synthesize Unique Yolk-Shelled $\mathrm{Fe}_{3} \mathrm{O}_{4} @$ Carbon with an Ultralong Cycling Life for Lithium Storage. Adv. Energy Mater. 2016, 6, 1502318. [CrossRef]

41. Wei Seh, Z.; Li, W.; Cha, J.J.; Zheng, G.; Yang, Y.; McDowell, M.T.; Hsu, P.-C.; Cui, Y. Sulphur-TiO 2 yolk-shell nanoarchitecture with internal void space for long-cycle lithium-sulphur batteries. Nat. Commun. 2013, 4, 1331. [CrossRef] [PubMed]

42. Ding, S.; Chen, J.S.; Qi, G.; Duan, X.; Wang, Z.; Giannelis, E.P.; Archer, L.A.; Lou, X.W. Formation of $\mathrm{SnO}_{2}$ Hollow Nanospheres inside Mesoporous Silica Nanoreactors. J. Am. Chem. Soc. 2011, 133, 21-23. [CrossRef] [PubMed]

43. Lu, S.; Tu, D.; Li, X.; Li, R.; Chen, X. A facile "ship-in-a-bottle" approach to construct nanorattles based on upconverting lanthanide-doped fluorides. Nano Res. 2016, 9, 187-197. [CrossRef]

44. Liu, C.; Li, J.; Qi, J.; Wang, J.; Luo, R.; Shen, J.; Sun, X.; Han, W.; Wang, L. Yolk-Shell Fe $0^{0} S i_{2}$ Nanoparticles as Nanoreactors for Fenton-like Catalytic Reaction. ACS Appl. Mater. Interfaces 2014, 6, 13167-13173. [CrossRef] [PubMed]

45. Shmakov, S.N.; Pinkhassik, E. Simultaneous templating of polymer nanocapsules and entrapped silver nanoparticles. Chem. Commun. 2010, 46, 7346-7348. [CrossRef]

46. Shmakov, S.N.; Jia, Y.; Pinkhassik, E. Selectively Initiated Ship-In-A-Bottle Assembly of Yolk-Shell Nanostructures. Chem. Mater. 2014, 26, 1126-1132. [CrossRef]

47. Zhang, J.; Wang, K.; Xu, Q.; Zhou, Y.; Cheng, F.; Guo, S. Beyond Yolk-Shell Nanoparticles: $\mathrm{Fe}_{3} \mathrm{O}_{4} @ \mathrm{Fe}_{3} \mathrm{C}$ Core@Shell Nanoparticles as Yolks and Carbon Nanospindles as Shells for Efficient Lithium Ion Storage. ACS Nano 2015, 9, 3369-3376. [CrossRef]

48. Teng, Z.; Wang, S.; Su, X.; Chen, G.; Liu, Y.; Luo, Z.; Luo, W.; Tang, Y.; Ju, H.; Zhao, D.; et al. Facile Synthesis of Yolk-Shell Structured Inorganic-Organic Hybrid Spheres with Ordered Radial Mesochannels. Adv. Mater. 2014, 26, 3741-3747. [CrossRef]

49. Zhang, Q.; Zhang, T.; Ge, J.; Yin, Y. Permeable Silica Shell through Surface-Protected Etching. Nano Lett. 2008, 8, 2867-2871. [CrossRef]

50. Xu, W.; Wang, J.; Ding, F.; Chen, X.; Nasybulin, E.; Zhang, Y.; Zhang, J.-G. Lithium metal anodes for rechargeable batteries. Energy Environ. Sci. 2014, 7, 513-537. [CrossRef]

51. Kim, H.; Jeong, G.; Kim, Y.-U.; Kim, J.-H.; Park, C.-M.; Sohn, H.-J. Metallic anodes for next generation secondary batteries. Chem. Soc. Rev. 2013, 42, 9011-9034. [CrossRef] [PubMed]

52. Mogi, R.; Inaba, M.; Jeong, S.-K.; Iriyama, Y.; Abe, T.; Ogumi, Z. Effects of Some Organic Additives on Lithium Deposition in Propylene Carbonate. J. Electrochem. Soc. 2002, 149, A1578-A1583. [CrossRef]

53. Liang, Z.; Lin, D.; Zhao, J.; Lu, Z.; Liu, Y.; Liu, C.; Lu, Y.; Wang, H.; Yan, K.; Tao, X.; et al. Composite lithium metal anode by melt infusion of lithium into a 3D conducting scaffold with lithiophilic coating. Proc. Natl. Acad. Sci. USA 2016, 113, 2862-2867. [CrossRef] [PubMed]

54. McDowell, M.T.; Lee, S.W.; Nix, W.D.; Cui, Y. 25th Anniversary Article: Understanding the Lithiation of Silicon and Other Alloying Anodes for Lithium-Ion Batteries. Adv. Mater. 2013, 25, 4966-4985. [CrossRef]

55. Xu, K. Nonaqueous Liquid Electrolytes for Lithium-Based Rechargeable Batteries. Chem. Rev. 2004, 104, 4303-4418. [CrossRef]

56. Xiao, X.; Lu, P.; Ahn, D. Ultrathin Multifunctional Oxide Coatings for Lithium Ion Batteries. Adv. Mater. 2011, 23, 3911-3915. [CrossRef]

57. Meng, X.; Yang, X.-Q.; Sun, X. Emerging Applications of Atomic Layer Deposition for Lithium-Ion Battery Studies. Adv. Mater. 2012, 24, 3589-3615. [CrossRef] 
58. Khalifa, H.; El-Safty, S.A.; Reda, A.; Shenashen, M.A.; Eid, A.I. Anisotropic alignments of hierarchical $\mathrm{Li}_{2} \mathrm{SiO}_{3} / \mathrm{TiO}_{2} @$ nano-C anode//LiMnPO4@nano-C cathode architectures for full-cell lithium-ion battery. Natl. Sci. Rev. 2020. [CrossRef]

59. Li, H.-H.; Wang, J.-W.; Wu, X.-L.; Sun, H.-Z.; Yang, F.-M.; Wang, K.; Zhang, L.-L.; Fan, C.-Y.; Zhang, J.-P. A novel approach to prepare $\mathrm{Si} / \mathrm{C}$ nanocomposites with yolk-shell structures for lithium ion batteries. RSC Adv. 2014, 4, 36218-36225. [CrossRef]

60. Pan, L.; Wang, H.; Gao, D.; Chen, S.; Tan, L.; Li, L. Facile synthesis of yolk-shell structured Si-C nanocomposites as anodes for lithium-ion batteries. Chem. Commun. 2014, 50, 5878-5880. [CrossRef]

61. Su, L.; Xie, J.; Xu, Y.; Wang, L.; Wang, Y.; Ren, M. Preparation and lithium storage performance of yolk-shell Si@void@C nanocomposites. Phys. Chem. Chem. Phys. 2015, 17, 17562-17565. [CrossRef] [PubMed]

62. Ru, Y.; Evans, D.G.; Zhu, H.; Yang, W. Facile fabrication of yolk-shell structured porous Si-C microspheres as effective anode materials for Li-ion batteries. RSC Adv. 2014, 4, 71-75. [CrossRef]

63. Yang, J.; Wang, Y.-X.; Chou, S.-L.; Zhang, R.; Xu, Y.; Fan, J.; Zhang, W.-X.; Kun Liu, H.; Zhao, D.; Xue Dou, S. Yolk-shell silicon-mesoporous carbon anode with compact solid electrolyte interphase film for superior lithium-ion batteries. Nano Energy 2015, 18, 133-142. [CrossRef]

64. Zhong, L.; Kwok, T.; Mangolini, L. Spray pyrolysis of yolk-shell particles and their use for anodes in lithium-ion batteries. Electrochem. Commun. 2015, 53, 1-5. [CrossRef]

65. Yang, L.Y.; Li, H.Z.; Liu, J.; Sun, Z.Q.; Tang, S.S.; Lei, M. Dual yolk-shell structure of carbon and silica-coated silicon for high-performance lithium-ion batteries. Sci. Rep. 2015, 5, 10908. [CrossRef]

66. Hong, Y.J.; Kang, Y.C. General Formation of Tin Nanoparticles Encapsulated in Hollow Carbon Spheres for Enhanced Lithium Storage Capability. Small 2015, 11, 2157-2163. [CrossRef]

67. Chen, P.; Wu, F.; Wang, Y. Four-Layer Tin-Carbon Nanotube Yolk-Shell Materials for High-Performance Lithium-Ion Batteries. ChemSusChem 2014, 7, 1407-1414. [CrossRef]

68. Ni, W.; Cheng, J.; Shi, L.; Li, X.; Wang, B.; Guan, Q.; Huang, L.; Gu, G.; Li, H. Integration of Sn/C yolk-shell nanostructures into free-standing conductive networks as hierarchical composite 3D electrodes and the Li-ion insertion/extraction properties in a gel-type lithium-ion battery thereof. J. Mater. Chem. A 2014, 2, 19122-19130. [CrossRef]

69. Ni, W.; Wang, Y.; Xu, R. Formation of Sn@C Yolk-Shell Nanospheres and Core-Sheath Nanowires for Highly Reversible Lithium Storage. Part. Part. Syst. Charact. 2013, 30, 873-880. [CrossRef]

70. Zhang, W.-M.; Hu, J.-S.; Guo, Y.-G.; Zheng, S.-F.; Zhong, L.-S.; Song, W.-G.; Wan, L.-J. Tin-Nanoparticles Encapsulated in Elastic Hollow Carbon Spheres for High-Performance Anode Material in Lithium-Ion Batteries. Adv. Mater. 2008, 20, 1160-1165. [CrossRef]

71. Yu, Y.; Gu, L.; Wang, C.; Dhanabalan, A.; van Aken, P.A.; Maier, J. Encapsulation of Sn@carbon Nanoparticles in Bamboo-like Hollow Carbon Nanofibers as an Anode Material in Lithium-Based Batteries. Angew. Chem. Int. Ed. 2009, 48, 6485-6489. [CrossRef]

72. Wang, J.; Li, W.; Wang, F.; Xia, Y.; Asiri, A.M.; Zhao, D. Controllable synthesis of $\mathrm{SnO}_{2} @ \mathrm{C}$ yolk-shell nanospheres as a high-performance anode material for lithium ion batteries. Nanoscale 2014, 6, 3217-3222. [CrossRef] [PubMed]

73. Li, J.; Wu, P.; Ye, Y.; Wang, H.; Zhou, Y.; Tang, Y.; Lu, T. Designed synthesis of $\mathrm{SnO}_{2} @ \mathrm{C}$ yolk-shell spheres for high-performance lithium storage. CrystEngComm 2014, 16, 517-521. [CrossRef]

74. Song, H.; Li, N.; Cui, H.; Wen, X.; Wei, X.; Wang, C. Significantly improved high-rate Li-ion batteries anode by encapsulating tin dioxide nanocrystals into mesotunnels. CrystEngComm 2013, 15, 8537-8543. [CrossRef]

75. Guo, H.; Mao, R.; Tian, D.; Wang, W.; Zhao, D.; Yang, X.; Wang, S. Morphology-controlled synthesis of $\mathrm{SnO}_{2} / \mathrm{C}$ hollow core-shell nanoparticle aggregates with improved lithium storage. J. Mater. Chem. A 2013, 1, 3652-3658. [CrossRef]

76. Hong, Y.J.; Son, M.Y.; Kang, Y.C. One-Pot Facile Synthesis of Double-Shelled $\mathrm{SnO}_{2}$ Yolk-Shell-Structured Powders by Continuous Process as Anode Materials for Li-ion Batteries. Adv. Mater. 2013, 25, 2279-2283. [CrossRef] [PubMed]

77. Li, S.; Niu, J.; Zhao, Y.C.; So, K.P.; Wang, C.; Wang, C.A.; Li, J. High-rate aluminium yolk-shell nanoparticle anode for Li-ion battery with long cycle life and ultrahigh capacity. Nat. Commun. 2015, 6, 7872. [CrossRef]

78. Son, M.Y.; Hong, Y.J.; Kang, Y.C. Superior electrochemical properties of $\mathrm{Co}_{3} \mathrm{O}_{4}$ yolk-shell powders with a filled core and multishells prepared by a one-pot spray pyrolysis. Chem. Commun. 2013, 49, 5678-5680. [CrossRef] 
79. Kim, M.H.; Hong, Y.J.; Kang, Y.C. Electrochemical properties of yolk-shell and hollow $\mathrm{CoMn}_{2} \mathrm{O}_{4}$ powders directly prepared by continuous spray pyrolysis as negative electrode materials for lithium ion batteries. RSC Adv. 2013, 3, 13110-13114. [CrossRef]

80. Zhao, Y.; Feng, Z.; Xu, Z.J. Yolk-shell $\mathrm{Fe}_{2} \mathrm{O}_{3} @ \mathrm{C}$ composites anchored on MWNTs with enhanced lithium and sodium storage. Nanoscale 2015, 7, 9520-9525. [CrossRef]

81. Zhao, Y.; Li, J.; Wu, C.; Ding, Y.; Guan, L. A Yolk-Shell $\mathrm{Fe}_{3} \mathrm{O}_{4} @ \mathrm{C}$ Composite as an Anode Material for High-Rate Lithium Batteries. ChemPlusChem 2012, 77, 748-751. [CrossRef]

82. Zhang, H.; Zhou, L.; Noonan, O.; Martin, D.J.; Whittaker, A.K.; Yu, C. Tailoring the Void Size of Iron Oxide@Carbon Yolk-Shell Structure for Optimized Lithium Storage. Adv. Funct. Mater. 2014, 24, 4337-4342. [CrossRef]

83. Son, M.Y.; Hong, Y.J.; Lee, J.-K.; Chan Kang, Y. One-pot synthesis of $\mathrm{Fe}_{2} \mathrm{O}_{3}$ yolk-shell particles with two, three, and four shells for application as an anode material in lithium-ion batteries. Nanoscale 2013, 5, 11592-11597. [CrossRef] [PubMed]

84. Lim, J.; Um, J.H.; Ahn, J.; Yu, S.-H.; Sung, Y.-E.; Lee, J.-K. Soft Template Strategy to Synthesize Iron Oxide-Titania Yolk-Shell Nanoparticles as High-Performance Anode Materials for Lithium-Ion Battery Applications. Chem. Eur. J. 2015, 21, 7954-7961. [CrossRef]

85. Wang, S.; Xiao, C.; Xing, Y.; Xu, H.; Zhang, S. Formation of a stable carbon framework in a MnO yolk-shell sphere to achieve exceptional performance for a Li-ion battery anode. J. Mater. Chem. A 2015, 3, 15591-15597. [CrossRef]

86. Cai, Z.; Xu, L.; Yan, M.; Han, C.; He, L.; Hercule, K.M.; Niu, C.; Yuan, Z.; Xu, W.; Qu, L.; et al. Manganese Oxide/Carbon Yolk-Shell Nanorod Anodes for High Capacity Lithium Batteries. Nano Lett. 2015, 15, 738-744. [CrossRef]

87. Zhang, X.; Song, X.; Gao, S.; Xu, Y.; Cheng, X.; Zhao, H.; Huo, L. Facile synthesis of yolk-shell $\mathrm{MoO}_{2}$ microspheres with excellent electrochemical performance as a Li-ion battery anode. J. Mater. Chem. A 2013, 1, 6858-6864. [CrossRef]

88. Liu, L.; Guo, H.; Liu, J.; Qian, F.; Zhang, C.; Li, T.; Chen, W.; Yang, X.; Guo, Y. Self-assembled hierarchical yolk-shell structured NiO@C from metal-organic frameworks with outstanding performance for lithium storage. Chem. Commun. 2014, 50, 9485-9488. [CrossRef]

89. Song, H.; Cui, H.; Wang, C. Abnormal Cyclibility in Ni@Graphene Core-Shell and Yolk-Shell Nanostructures for Lithium Ion Battery Anodes. ACS Appl. Mater. Interfaces 2014, 6, 13765-13769. [CrossRef]

90. Kong, S.; Dai, R.; Li, H.; Sun, W.; Wang, Y. Microwave Hydrothermal Synthesis of Ni-based Metal-Organic Frameworks and Their Derived Yolk-Shell NiO for Li-Ion Storage and Supported Ammonia Borane for Hydrogen Desorption. ACS Sustain. Chem. Eng. 2015, 3, 1830-1838. [CrossRef]

91. Choi, S.H.; Kang, Y.C. Ultrafast Synthesis of Yolk-Shell and Cubic NiO Nanopowders and Application in Lithium Ion Batteries. ACS Appl. Mater. Interfaces 2014, 6, 2312-2316. [CrossRef]

92. Ahn, J.H.; Park, G.D.; Kang, Y.C.; Lee, J.-H. Phase-pure $\beta-\mathrm{NiMoO}_{4}$ yolk-shell spheres for high-performance anode materials in lithium-ion batteries. Electrochim. Acta 2015, 174, 102-110. [CrossRef]

93. Yu, L.; Guan, B.; Xiao, W.; Lou, X.W. Formation of Yolk-Shelled Ni-Co Mixed Oxide Nanoprisms with Enhanced Electrochemical Performance for Hybrid Supercapacitors and Lithium Ion Batteries. Adv. Energy Mater. 2015, 5, 1500981. [CrossRef]

94. Jiang, L.; Qu, Y.; Ren, Z.; Yu, P.; Zhao, D.; Zhou, W.; Wang, L.; Fu, H. In Situ Carbon-Coated Yolk-Shell V $\mathrm{V}_{2} \mathrm{O}_{3}$ Microspheres for Lithium-Ion Batteries. ACS Appl. Mater. Interfaces 2015, 7, 1595-1601. [CrossRef]

95. Xie, Q.; Zhang, X.; Wu, X.; Wu, H.; Liu, X.; Yue, G.; Yang, Y.; Peng, D.-L. Yolk-shell ZnO-C microspheres with enhanced electrochemical performance as anode material for lithium ion batteries. Electrochim. Acta 2014, 125, 659-665. [CrossRef]

96. Xie, Q.; Ma, Y.; Zeng, D.; Wang, L.; Yue, G.; Peng, D.-L. Facile fabrication of various zinc-nickel citrate microspheres and their transformation to $\mathrm{ZnO}-\mathrm{NiO}$ hybrid microspheres with excellent lithium storage properties. Sci. Rep. 2015, 5, 8351. [CrossRef]

97. Choi, S.H.; Kang, Y.C. Yolk-Shell, Hollow, and Single-Crystalline $\mathrm{ZnCo}_{2} \mathrm{O}_{4}$ Powders: Preparation Using a Simple One-Pot Process and Application in Lithium-Ion Batteries. ChemSusChem 2013, 6, 2111-2116. [CrossRef] 
98. Won, J.M.; Choi, S.H.; Hong, Y.J.; Ko, Y.N.; Kang, Y.C. Electrochemical properties of yolk-shell structured $\mathrm{ZnFe}_{2} \mathrm{O}_{4}$ powders prepared by a simple spray drying process as anode material for lithium-ion battery. Sci. Rep. 2014, 4, 5857. [CrossRef]

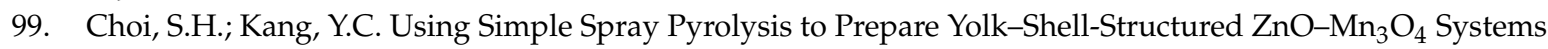
with the Optimum Composition for Superior Electrochemical Properties. Chem. Asia. J. 2014, 20, 3014-3018.

100. Qiu, W.; Jiao, J.; Xia, J.; Zhong, H.; Chen, L. A Self-Standing and Flexible Electrode of Yolk-Shell CoS 2 Spheres Encapsulated with Nitrogen-Doped Graphene for High-Performance Lithium-Ion Batteries. Chem. Eur. J. 2015, 21, 4359-4367. [CrossRef]

101. Ko, Y.N.; Choi, S.H.; Park, S.B.; Kang, Y.C. Preparation of Yolk-Shell and Filled Co9S8 Microspheres and Comparison of their Electrochemical Properties. Chem. Asian J. 2014, 9, 572-576. [CrossRef]

102. Ko, Y.N.; Choi, S.H.; Park, S.B.; Kang, Y.C. Hierarchical MoSe 2 yolk-shell microspheres with superior Na-ion storage properties. Nanoscale 2014, 6, 10511-10515. [CrossRef]

103. Choi, S.H.; Kang, Y.C. Synthesis for Yolk-shell-structured Metal Sulfide Powders with Excellent Electrochemical Performances for Lithium-ion Batteries. Small 2014, 10, 474-478. [CrossRef]

104. Won, J.M.; Lee, J.-H.; Kang, Y.C. Electrochemical Properties of Yolk-Shell-Structured Zn-Fe-S Multicomponent Sulfide Materials with a 1:2 Zn/Fe Molar Ratio. Chem. Eur. J. 2015, 21, 1429-1433. [CrossRef]

105. Jin, J.; Huang, S.-Z.; Li, Y.; Tian, H.; Wang, H.-E.; Yu, Y.; Chen, L.-H.; Hasan, T.; Su, B.-L. Hierarchical nanosheet-constructed yolk-shell $\mathrm{TiO}_{2}$ porous microspheres for lithium batteries with high capacity, superior rate and long cycle capability. Nanoscale 2015, 7, 12979-12989. [CrossRef]

106. Wang, X.; Wang, Y.; Yang, L.; Wang, K.; Lou, X.; Cai, B. Template-free synthesis of homogeneous yolk-shell $\mathrm{TiO}_{2}$ hierarchical microspheres for high performance lithium ion batteries. J. Power Sources 2014, 262, 72-78. [CrossRef]

107. Zhang, Y.; Wang, C.; Hou, H.; Zou, G.; Ji, X. Nitrogen Doped/Carbon Tuning Yolk-Like $\mathrm{TiO}_{2}$ and Its Remarkable Impact on Sodium Storage Performances. Adv. Energy Mater. 2016, 7, 1600173. [CrossRef]

108. Ding, S.; Wang, Y.; Hong, Z.; Lü, X.; Wan, D.; Huang, F. Biomolecule-Assisted Route to Prepare Titania Mesoporous Hollow Structures. Chem. Eur. J. 2011, 17, 11535-11541. [CrossRef]

109. Yang, K.M.; Ko, Y.N.; Yun, J.-Y.; Kang, Y.C. Preparation of $\mathrm{Li}_{4} \mathrm{Ti}_{5} \mathrm{O}_{12}$ Yolk-Shell Powders by Spray Pyrolysis and their Electrochemical Properties. Chem. Asian J. 2014, 9, 443-446. [CrossRef]

110. Kasavajjula, U.; Wang, C.; Appleby, A.J. Nano- and bulk-silicon-based insertion anodes for lithium-ion secondary cells. J. Power Sources 2007, 163, 1003-1039. [CrossRef]

111. Wu, X.-L.; Guo, Y.-G.; Wan, L.-J. Rational Design of Anode Materials Based on Group IVA Elements (Si, Ge, and Sn) for Lithium-Ion Batteries. Chem. Asian J. 2013, 8, 1948-1958. [CrossRef] [PubMed]

112. Wang, J.; Yu, Y.; Gu, L.; Wang, C.; Tang, K.; Maier, J. Highly reversible lithium storage in Si (core)-hollow carbon nanofibers (sheath) nanocomposites. Nanoscale 2013, 5, 2647-2650. [CrossRef]

113. Liu, L.; Xie, F.; Lyu, J.; Zhao, T.; Li, T.; Choi, B.G. Tin-based anode materials with well-designed architectures for next-generation lithium-ion batteries. J. Power Sources 2016, 321, 11-35. [CrossRef]

114. Courtney, I.A.; Dahn, J.R. Electrochemical and In Situ X-Ray Diffraction Studies of the Reaction of Lithium with Tin Oxide Composites. J. Electrochem. Soc. 1997, 144, 2045-2052. [CrossRef]

115. Gay, E.C.; Vissers, D.R.; Martino, F.J.; Anderson, K.E. Performance Characteristics of Solid Lithium-Aluminum Alloy Electrodes. J. Electrochem. Soc. 1976, 123, 1591-1596. [CrossRef]

116. Park, J.H.; Hudaya, C.; Kim, A.Y.; Rhee, D.K.; Yeo, S.J.; Choi, W.; Yoo, P.J.; Lee, J.K. Al-C hybrid nanoclustered anodes for lithium ion batteries with high electrical capacity and cyclic stability. Chem. Commun. 2014, 50, 2837-2840. [CrossRef]

117. Do, J.-S.; Weng, C.-H. Preparation and characterization of $\mathrm{CoO}$ used as anodic material of lithium battery. J. Power Sources 2005, 146, 482-486. [CrossRef]

118. Choi, S.H.; Lee, J.-K.; Kang, Y.C. Controllable synthesis of yolk-shell-structured metal oxides with seven to ten components for finding materials with superior lithium storage properties. Nanoscale 2014, 6, 12421-12425. [CrossRef] 
119. He, C.; Wu, S.; Zhao, N.; Shi, C.; Liu, E.; Li, J. Carbon-Encapsulated $\mathrm{Fe}_{3} \mathrm{O}_{4}$ Nanoparticles as a High-Rate Lithium Ion Battery Anode Material. ACS Nano 2013, 7, 4459-4469. [CrossRef]

120. Luo, J.; Liu, J.; Zeng, Z.; Ng, C.F.; Ma, L.; Zhang, H.; Lin, J.; Shen, Z.; Fan, H.J. Three-Dimensional Graphene Foam Supported $\mathrm{Fe}_{3} \mathrm{O}_{4}$ Lithium Battery Anodes with Long Cycle Life and High Rate Capability. Nano Lett. 2013, 13, 6136-6143. [CrossRef]

(C) 2020 by the author. Licensee MDPI, Basel, Switzerland. This article is an open access article distributed under the terms and conditions of the Creative Commons Attribution (CC BY) license (http://creativecommons.org/licenses/by/4.0/). 